\title{
The evolution of high-temperature mylonitic microfabrics: evidence from simple shearing of a quartz analogue (norcamphor)
}

\author{
MARCO HERWEGH and MARK R. HANDY*
}

\author{
Geologisches Institut, Universität Bern, Baltzerstrasse 1, CH-3012 Bern, Switzerland
}

(Received 24 October 1994; accepted in revised form 22 September 1995)

\begin{abstract}
Plane strain simple shearing of norcamphor $\left(\mathrm{C}_{7} \mathrm{H}_{10} \mathrm{O}\right)$ in a see-through deformation rig to a shear strain of $\gamma=10.5$ at a homologous temperature of $T_{\mathrm{h}}=0.81$ yields a microfabric similar to that of quartz in amphibolite facies mylonite. Synkinematic analysis of the norcamphor microfabric reveals that the development of a steady-state texture is linked to changes in the relative activities of several grain-scale mechanisms. Three stages of textural and microstructural evolution are distinguished: (1) rotation and shearing of the intracrystalline glide planes are accommodated by localized deformation along three sets of anastomozing microshears. A symmetrical $c$-axis girdle reflects localized pure shear extension along the main microshear set $\left(S_{\mathrm{a}}\right)$ oblique to the bulk shear zone boundary (abbreviated as SZB); (2) progressive rotation of the microshears into parallelism with the SZB increases the component of simple shear on the $S_{a}$ microshears. Grain-boundary migration recrystallization favours the survival of grains with slip systems oriented for easy glide. This is associated with a textural transition towards two stable $c$-axis point maxima whose skeletal outline is oblique with respect to the $S_{\text {a }}$ microshears and the SZB; and (3) at high shear strains $(\gamma>8)$, the microstructure, texture and mechanism assemblage are strain invariant, but strain continues to partition into rotating sets of microshears. Steady state is therefore a dynamic, heterogeneous condition involving the cyclic nucleation, growth and consumption of grains. Copyright (C) 1996 Elsevier Science Ltd
\end{abstract}

\section{INTRODUCTION}

Microfabrics preserve information about the thermal, kinematic and mechanical evolution of rocks and so have become valuable tools for reconstructing deformation history. Yet, the evolution of microfabrics in mylonitic rock is still rather poorly understood. A microfabric comprises all geometric and crystallographic features of a rock that are observable on the microscopic scale. Geometric elements such as grain boundaries, grain-shape preferred orientations (SPO), microshear zones and foliations are referred to generally as microstructures, whereas a preferred alignment of crystallographic axes (or crystallographic preferred orientation, CPO) within a mineral aggregate is often termed a texture (see Vernon 1976, p. 24 for a discussion of nomenclature).

A basic problem encountered when interpreting mylonitic microfabrics from naturally deformed rock is that both microstructure and texture are sensitive to a host of variables (review in Law 1990): the predeformational characteristics of the rock (i.e. grain size, composition), the strain path and strain configuration (i.e. finite strain and changes in the vorticity number), and the physical conditions of deformation (particularly temperature, strain rate and fluid composition). Another problem is that a given microfabric usually preserves only a short interval of the rock's total defor-

\footnotetext{
*Present address: Institut für Geowissenschaften, Justus-Liebig. Universität, Senckenbergstrasse 3, D-35390 Giessen, Germany. sg 10:5-J
}

mation history. Geologists have partly circumvented this problem by studying microfabric changes across strain gradients within mylonitic shear zones. Such studies document an increase in microfabric asymmetry into shear zones, supporting the notion that one or more slip systems rotate into an orientation that is subparallel to the bulk shearing plane (e.g. Lister \& Hobbs 1980, Schmid \& Casey 1986). However, strain paths inferred from strain gradients across shear zones can differ significantly from the actual strain paths of different parts of the sheared rock, especially if localization involved some hardening and broadening of the shear zone. Also, time and strain rate are rather poorly constrained in natural shear zones.

Computer modelling and laboratory experiments yield alternate, but no less problematic, insight into the mechanisms of microfabric evolution. Etchecopar's two-dimensional computer model (Etchecopar 1977) contains grains with only a single slip system that undergoes progressive, rigid-body rotation into an easy glide orientation. Grain fracturing is used to approximate the role of dynamic recrystallization in maintaining strain compatibility within the aggregate. Although the resulting texture is quite realistic, the model microstructure is not like that observed in rocks because of the gaps and overlaps that develop between neighbouring grains. Lister $e$ al . (1978) presented a three-dimensional computer model based on the Taylor-Bishop-Hill (TBH) theory that imposes homogeneous strain accommodated by the rotation of slip systems towards orientations for which the overall rate of strain energy dissipation is minimized. Thus, the slip systems within the grains only 
undergo shear-induced vorticity (Lister 1982, Lister \& Williams 1983). Viscoplastic, self-consistent (VPSC) models (Wenk et al. 1989) allow a limited degree of strain heterogeneity on the granular scale within the deforming aggregate, but yield textures similar to those of TBH models (Wenk et al. 1989). Neither the TBH nor the VPSC models generate realistic simple shear textures, partly because they do not account for the effects of dynamic recrystallization. More recently, Etchecopar and Vasseur (1987), Jessell (1988) and Jessell \& Lister (1990) incorporated algorithms to simulate such effects on microfabric evolution. In the latter two models, grains that are favourably oriented for intracrystalline glide consume poorly oriented grains. Although the resulting model microfabrics are more realistic, Etchccopar and Vasseur's new model simulates dynamic recrystallization in a very unmechanistic way whereas Jessell's new model is still based on TBH theory and its unrealistic assumption of homogeneous strain. Clearly then, the computer models reviewed above incorporate simplifying assumptions that allow them to replicate some, but not all, relevant aspects of microfabric evolution in nature.

Similar to naturally deformed rocks, rock samples that are experimentally deformed at high pressures and temperatures in triaxial or torsional deformational rigs (e.g. Tullis \& Tullis 1986) contain microfabrics frozen in during a relatively short time interval near the end of the deformation. Thus, samples are deformed to different strains along a pre-determined strain path in order to investigate progressive microfabric evolution (Tullis $e t$ al. 1973, Hirth \& Tullis 1992, Gleason et al. 1993). Of course, natural rock deformation is a dynamic process involving microfabric changes with increasing strain and time. Even during steady-state deformation, parts of the microfabric change continuously while the overall microfabric remains the same (Means 1981).

In light of shortcomings with existing experimental and theoretical studies of microfabric cvolution, wc opted to deform an organic, quartz-analogue material (norcamphor) in plane strain, simple shear directly under the optical microscope (Means 1980, 1989b, Urai \& Humphreys 1980, Jessell 1986, Ree 1990, Bons 1993). The advantage of this in situ method is that one can monitor the microfabric continuously during deformation. In this paper, we report on a series of experiments on norcamphor designed to simulate microfabric evolution in natural, high-temperature quartz mylonite. We describe how the evolution of a dynamic, steadystate microfabric in norcamphor is closely linked to changes in strain partitioning on the sample scale as well as to the relative activities of deformational and strain accommodation mechanisms. The similarity of our experimental norcamphor microfabrics with natural quartz microfabrics in amphibolite facies mylonite forms the basis for a kinematic model of texture and microstructure development in polycrystalline quartz. Finally, we discuss the implications of this experimental work for the kinematic interpretation of microfabrics in naturally deformed rock.

\section{FXPERIMENTAL CONFIGURATION AND CONDITIONS}

We used a Means-Urai rig (Means 1989b) to shear the norcamphor sample between two glass plates with frosted grips (see Fig. 1a and Jessell 1986, Means 1989b for a detailed description of this configuration). Norcamphor $\left(\mathrm{C}_{7} \mathrm{H}_{10} \mathrm{O}\right.$; Bons 1993) displays uniaxial negative optical properties, indicating that its crystallography is tetragonal, trigonal or hexagonal. Norcamphor sublimates quickly at room temperature, precluding closer identification of its crystallography and potential glide systems with X-ray diffractometry. However, norcamphor precipitated from a vapour onto glass surfaces produces dendritic crystals with hexagonal symmetry (see Fig. 2.5 in Bons 1993), consistent with a hexagonal crystallography. What makes norcamphor an attractive analogue material is that its deformational microfabric at room temperature and a shear strain rate of $10^{-4} \mathrm{~s}^{-1}$ closely resembles that observed in high-temperature quartzite mylonite. Creep tests on norcamphor indicate that dislocation creep is the dominant deformation mechanism under these conditions (Bons 1993).

Samples were prepared by mixing norcamphor with small amounts of fine-grained corundum grinding powder that served as passive strain markers during the experiments (see below). The powder grains were so small $(5-20 \mu \mathrm{m})$ that they did not noticeably affect the motion of the norcamphor grain boundaries during deformation. The norcamphor containing the powder grains was then cold pressed in a hand-driven pneumatic press for $20 \mathrm{~s}$ and manually inserted between the glass plates of the deformation rig. The samples were subsequently hot pressed in the rig for $96 \mathrm{~h}$ at $45^{\circ} \mathrm{C}$ by placing a weight on top of the glass plates, perpendicular to the plane of observation (Fig. 1b). This induced coaxial flattening parallel to the glass plates, with a shortening strain of $50 \%$ perpendicular to the plates. The plane of observation therefore lies parallel to the $X^{\prime} Z^{\prime}$ fabric plane during hot pressing (Fig. 1b), but parallel to the $X Z$ fabric plane of the later simple shear experiments (Fig. 1c). Coaxial flattening during sample preparation induced concentric $c$-axis small circle patterns about the $\sigma_{1}$ direction (see initial $c$-axis distribution, Figs. $1 \mathrm{~b} \& \mathrm{c}$ and pole diagram at top of column 2 in Fig. 2). However, this texture disintegrated by a shear strain of $\gamma=1-2$ and fortunately did not contain any of the steady state $c$-axis orientations attained during the simple shearing experiments. The advantage of this initial flattening texture is that it allowed us to study the processes involved in creating a steady-state microfabric in simple shear with completely new textural elements (compare pole diagrams at the top and bottom of column 2 in Fig. 2). The thickness of the norcamphor samples was between 50 and $100 \mu \mathrm{m}$, dimensions somewhat larger than the average diameter of the smallest, dynamically recrystallized grains nucleated during the experiment.

During the simple shear experiments, both the upper and lower glass plates were coated with silicon oil in 
Experimental evolution of mylonitic fabrics

a)

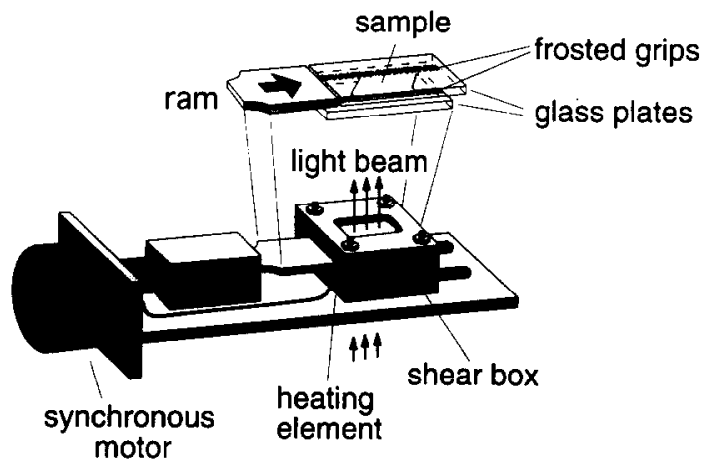

b)

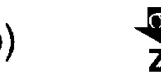

$\mathbf{Z}^{\prime}$

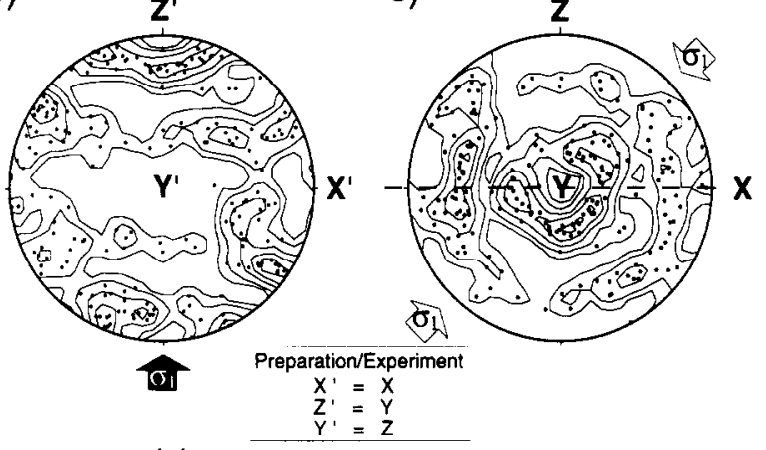

Fig. 1. (a) Diagram of the Urai see-through deformation apparatus. The norcamphor sample is sheared between two glass plates with frosted grips. The ram moves the upper glass plate with respect to the lower one. (b) Configuration, sample axes and texture during sample preparation as viewed perpendicular to the $X^{\prime} Z^{\prime}$ plane. Shortening perpendicular to the glass plates yields a coaxial fiattening texture comprising two small circle $c$-axis patterns about the $\sigma_{1}$ axis. (c) Configuration, sample axes and texture at the onset of simple shearing. The flattening texturc inherited from (b) is now viewed perpendicular to the XZ fabric plane in simple shear. When comparing (b) and (c), note that the $\sigma_{1}$-direction during coaxial hot pressing is parallel to the future $Y$ specimen axis during simple shearing. The texture in (c) is identical to that depicted at the top of the second column of Fig. 2. Contour intervals of equal area projections are $0.5,1,2,3$ and 4 times uniform distribution. Sample co-ordinates during sample preparation are indicated with a prime.

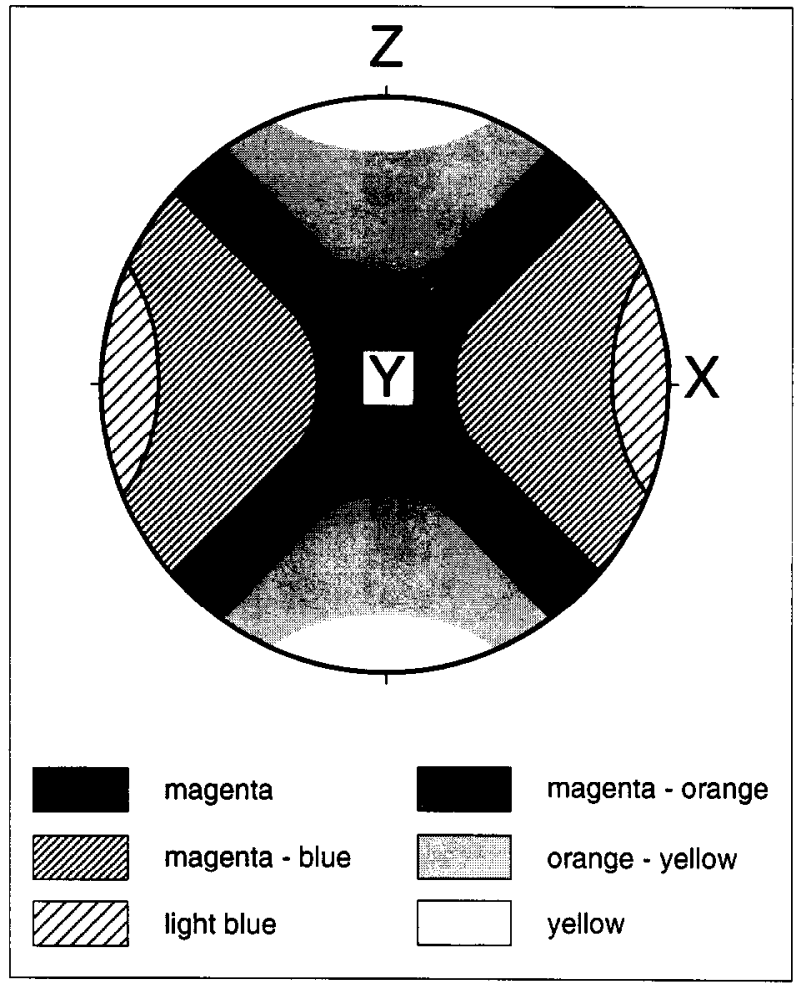

Fig. 3. Pole figure showing the relationship of norcamphor interference colours observed in thin section to norcamphor $c$ axis orientation and sample directions during the experiment. The colours were observed with the polarizer, analyser and condenser all rotated $45^{\circ}$ with respect to their usual position (see text for explanation). The orientation domains depicted in this figure are identical to those used in Figs. 2,5 and 6. The boxes in the lower part of the figure contain the shaded patterns corresponding to specific crystallographic orientations depicted in the pole diagram and used in the following figures.

Fig. 2 (on following pages). Norcamphor microfabric evolution for $\gamma=0$-10: bulk finite strain ellipses (first column), $c$-axes patterns comprising 200 measurements each (second column), microstructures (third column), finite strain grid with localization patterns (fourth column), and corresponding contours of axial ratios of the finite strain ellipse (fifth column). The last two pictures in the fifth column show microstructures containing rectangular subgrains with kinked basal planes (see text). The various shades and hatchings of grains in the microstructures represent interference colours that are keyed to $c$-axis orientation domains in the pole figures (see Fig. 3). Contour intervals in the top five pole figures are 1 , $2,3 \ldots$ times uniform distribution, in the bottom two pole figures $1,5,10,15 \ldots$ times uniform distribution. $S_{\mathrm{a}}$ and $\mathrm{SZB}$ refer to $S_{\mathrm{a}}$ microshears and shear zone boundary, respectively. 


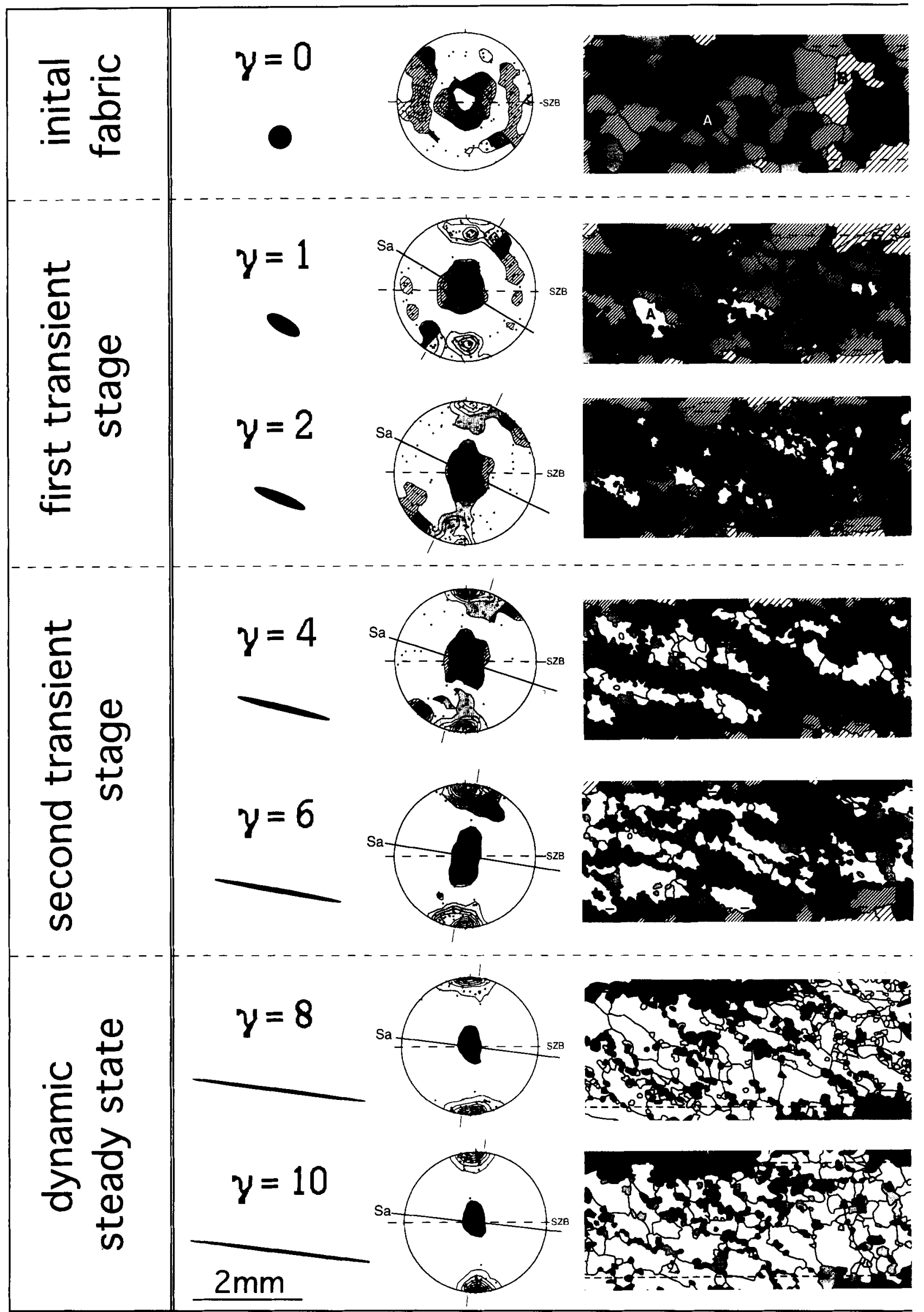

Fig. 2(a) 

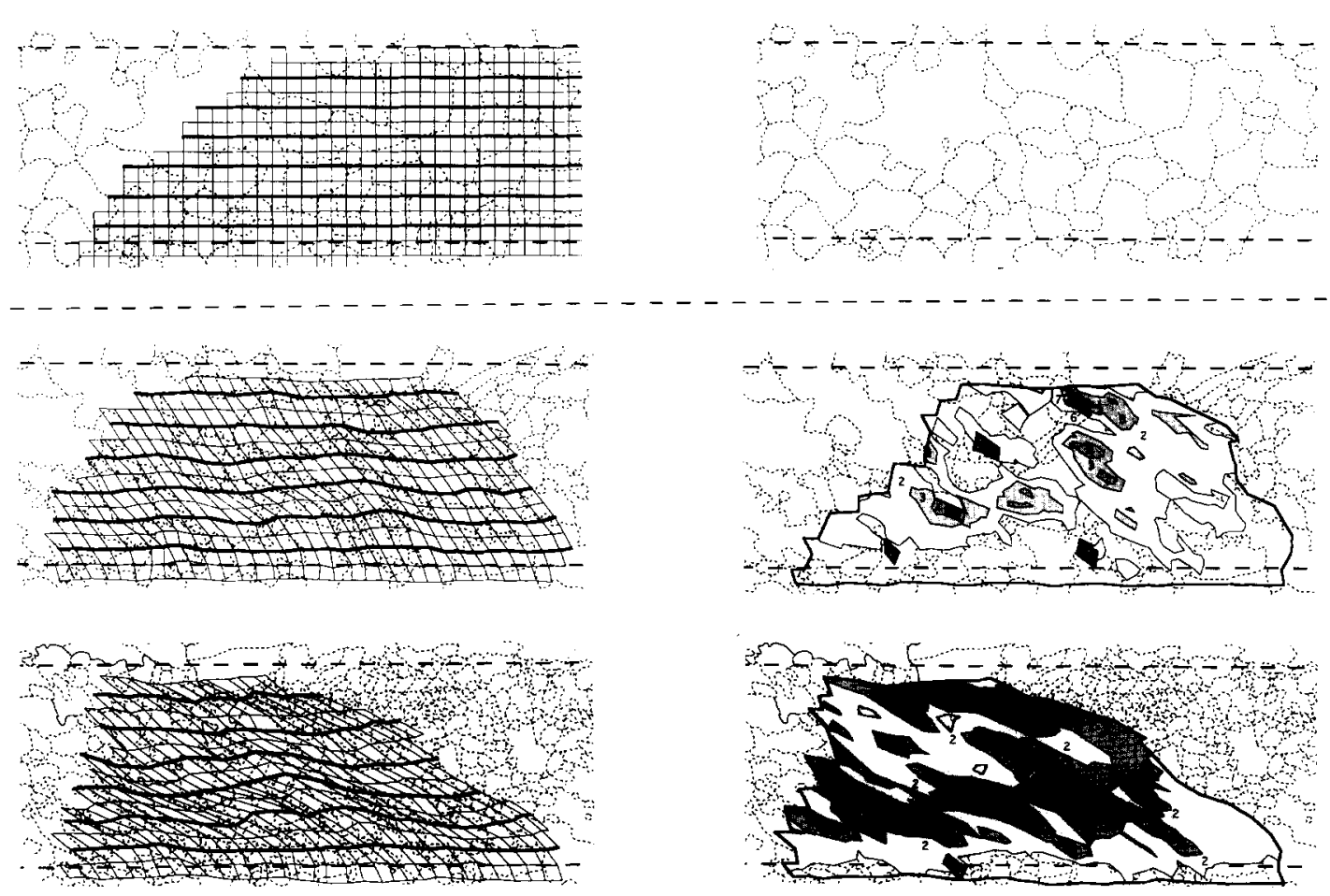
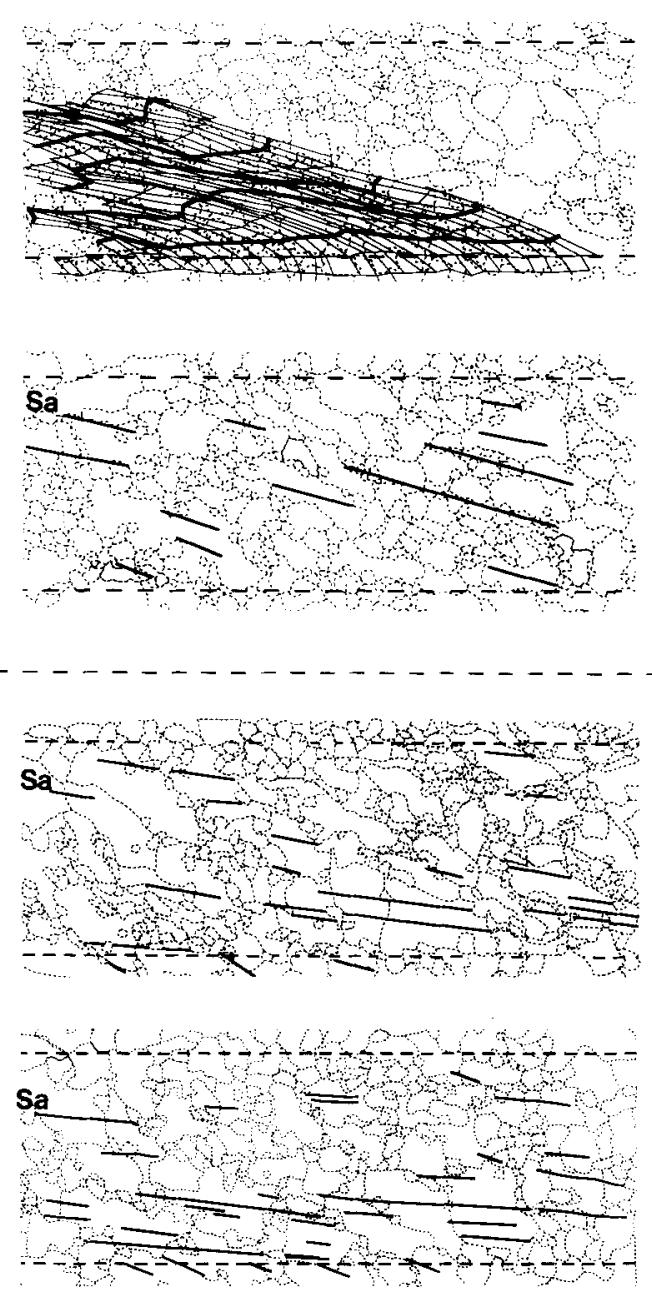

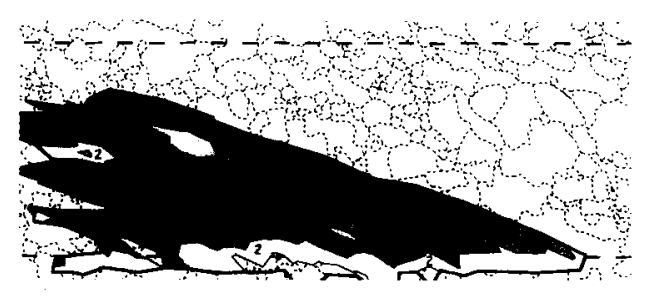

\section{axial ratios}

\begin{tabular}{|c|c|c|}
\hline 2 & & 16 \\
\hline 12 & 8 & 32 \\
\hline & 12 & 64 \\
\hline
\end{tabular}
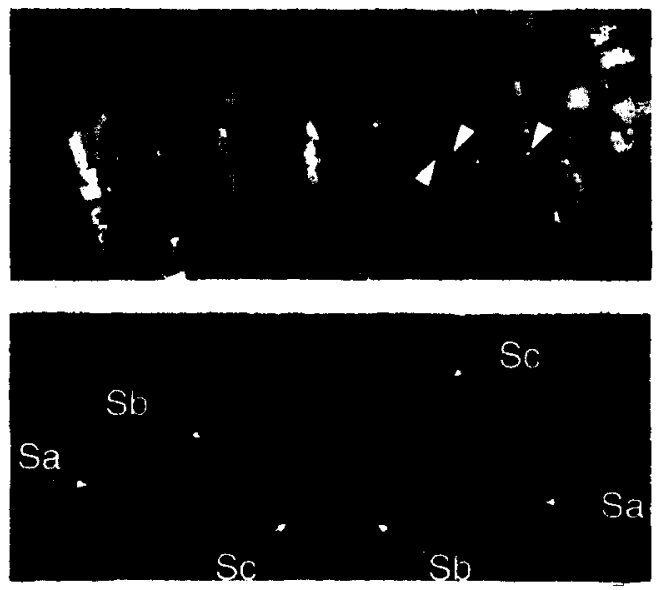

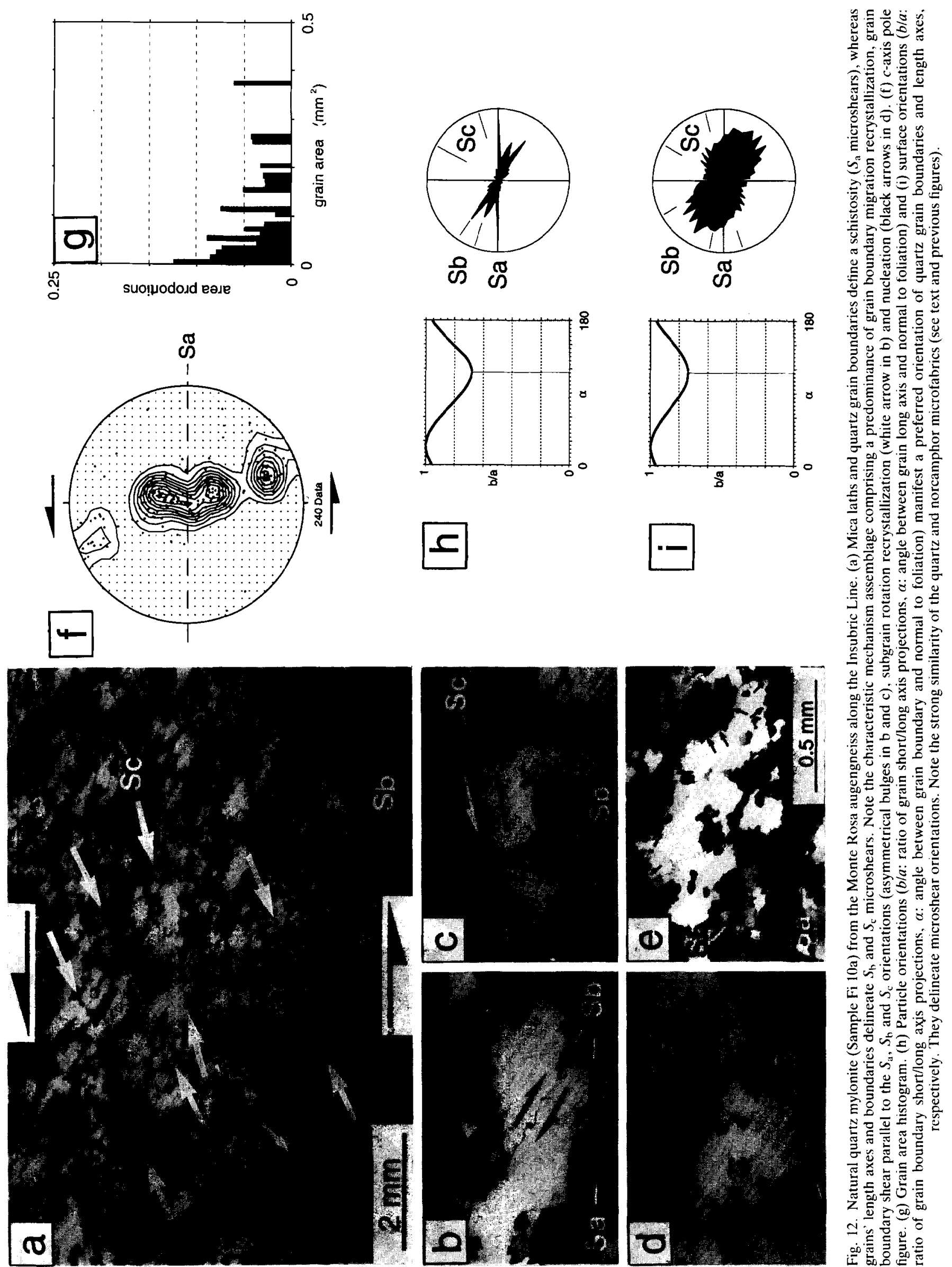
을.

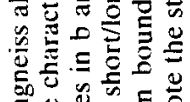
50

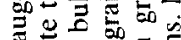

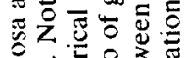

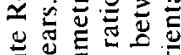

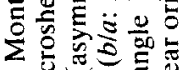

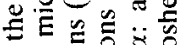
हc.

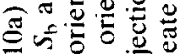

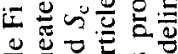
들.

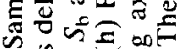

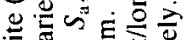

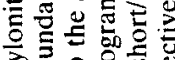

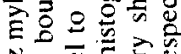
을 西

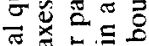

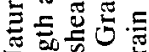

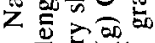
승

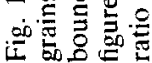


order to reduce the friction between the norcamphor sample and the unfrosted areas of the glass plates. Despite these precautions, slight departures from ideal plane strain, simple shear conditions occurred during the low strain stage of the experiments $(\gamma \leqslant 0.5)$, possibly due to minor thinning of the samples in the $Y$ fabric direction.

All experiments were conducted at a homologous temperature ( $\left.T / T_{\text {melting }}\right)$ for norcamphor of 0.81 and at a shear strain rate of $5.5 \times 10^{-4} \mathrm{~s}^{-1}$. Finite shear strains of up to $\gamma=10.5$ were attained with the configuration of glass plates described above. When tracking the textural evolution of norcamphor under the microscope, we enhanced the interference colours of the grains by rotating the microscope polarizer, the analyser and the compensator $45^{\circ}$ counterclockwise from their usual N-S orientation in the microscope. This allowed us to distinguish grains with six types of interference colours (Fig. 3). For each successive experiment to a given shear strain, such grains were measured on the U-stage to define six corresponding domains of crystallographic orientation (pole figure in Fig. 3). In Figs. 2 and 3, these six orientational domains are presented by various diagonally hatched patterns and shades of gray. Note that this technique is really just a generalized form of the AVA method (Achsenverteilungsanalyse) previously described by Ramsauer (1941) and Sander (1950).

The evolving microstructure was recorded continuously on videotape and photographed every $15 \mathrm{~min}$. Numbering and digitizing the position of the corundum marker particles in unpolarized photographs of the deforming samples facilitated the calculation of a strain grid for each strain increment (method and program described in Bons 1993). The deformed grid and contoured finite axial strain ratios could only be calculated for shear strains of up to $\gamma=4$ (fourth and fifth columns in Fig. 2), because the marker particles moved out of the microscopic field of view at higher strains. The particle and surface orientations of norcamphor grains were analysed with the aid of the computer programs PAROR and SURFOR (Panozzo 1983, 1984). Based on a projection of the long and short axes of digitized grain boundary outlines onto orthogonal $x$ - and $y$-axes, PAROR calculates both the axial ratio of grains and the angle between a grain's long axis and the normal of the $z$ co-ordinate axis (which in our case was chosen to corre- spond to the SZB). SURFOR uses the same projection to calculate these parameters for small segments of grain boundaries rather than for entire grains. Grain area proportions were calculated from digitized line drawings of grain boundaries with the public domain program Image 1.28 (Rasband 1992).

\section{EVOLUTION OF TEXTURE AND MICROSTRUCTURE IN NORCAMPHOR}

The development of a steady-state microfabric in norcamphor is closely linked to variations in strain partitioning on the sample scale as well as in the combination of active, grain-scale mechanisms. We use the term 'mechanism' in a broad sense to refer to a deformation mechanism or any process that is visibly related to syntectonic changes in the microfabric. A mechanism is described as 'active' when it is interpreted to effect such changes during the experiment. In our norcamphor experiments, we distinguished five such grain-scale mechanisms with the criteria listed in Table 1. Although the evolution of the microfabric is continuous, we discerned two transient stages based on strain-dependent changes in the texture and microstructure.

\section{First transient stage}

At very low strains $(\gamma<0.3)$, intracrystalline glideinduced vorticity (or 'shear-induced component of vorticity', Lister \& Williams 1983) of the entire aggregate involves predominantly intracrystalline slip. The deformation appears homogeneous on the scale of the sample. With higher strain $(0.3<\gamma<1)$, the deformation becomes increasingly heterogeneous and a strong SPO develops at $60^{\circ}$ to the shear zone boundary (Fig. 2 column 3, see also Rce 1991). This SPO is defined by the long axes of individual grains (Fig. 4) and persists to steady state. The detailed strain analysis in Fig. 5 shows that some grains within the aggregate remain relatively undeformed and that their $c$-axes rotate with respect to those of adjacent grains. Thus, rigid-body rotation (Ree 1990) or spin (Lister \& Williams 1983) allows individual grains or clusters of grains whose glide systems are poorly oriented for slip (diagonally hatched grains in Fig. 2, column 3 and Figs. 5 and 6) to acquire an

Table 1 .

\begin{tabular}{ll}
\hline Fabric-accommodating mechanisms on the grain scale & Criteria for recognition and examples \\
\hline Glide-induced vorticity (dislocation glide) & $\begin{array}{l}\text { Moderate to high incremental strain in grains with rotating } c \text {-axes (e.g. grain A at } \\
\text { top of column 3 in Fig. 2) }\end{array}$ \\
Rigid-body rotation & $\begin{array}{l}\text { Low incremental strain in grains surrounded by high strain domains; } c \text {-axes rotate } \\
\text { with grain shape (e.g. Fig. } 5 \text { ) }\end{array}$ \\
Subgrain rotation recrystallization & $\begin{array}{l}\text { Progressive rotation of relatively small, crystallographically homogeneous } \\
\text { domains adjacent to largcr strained grains (e.g. bottom two micrographs of } \\
\text { column } 5 \text { in Fig. 2) }\end{array}$ \\
Grain boundary migration recrystallization & $\begin{array}{l}\text { Bulged grain boundaries that migrate in time and space (e.g. Figs. 2 and 6) } \\
\text { Sudden appearance and growth of very small, polygonal grains (e.g. second } \\
\text { micrograph from bottom of column 5 in Fig. 2) }\end{array}$
\end{tabular}




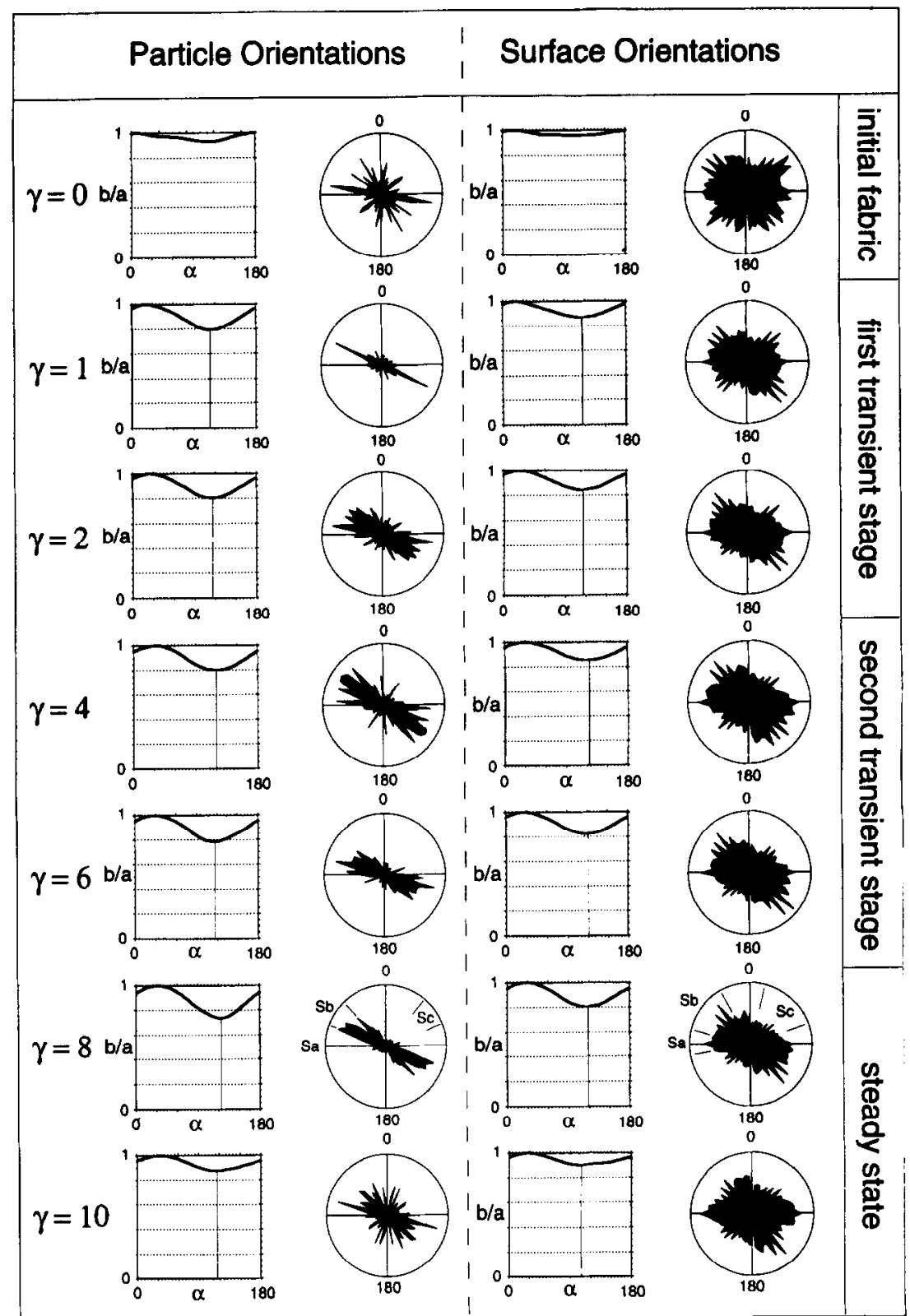

Fig. 4. Evolution of particle and surface orientations with strain. Diagrams in the first column show the average grain ratio, $b / a$, and the angle, $\alpha . a=$ projection of grain long axis onto the $x$ co-ordinate axis, $b=$ projection of grain short axis onto the $y$ co-ordinate axis, $b / a=$ axial ratio of the short to long axis projections, $a=$ arigle between grain long axis and the $z \mathrm{co}$ ordinate axis (normal to the SZB). The rose diagram in the second column presents the average long axis orientation of grains $(\alpha)$ with respect to the horizontal SBZ. Diagrams in the third column show the average $b / a$ ratio and angle $(\alpha)$ of the grain boundary segments. The rose diagrams in the fourth column represent the orientations of these grain boundary segments with respect to the horizontal SZB. Particle orientations and surface orientations indicate a preferred orientation, respectively, of norcamphor grain boundaries and of grain length axes. They delineate the orientations of the $S_{\mathrm{a}}, S_{\mathrm{b}}$, and $S_{\mathrm{c}}$ microshears. After a shear strain of 2 , the particles and grain boundaries have already attained a stable orientation defined by particle ratios of $b / a=0.8$ and $\alpha=122^{\circ}$ and grain boundary segment ratios of $b / a=0.85$ and $\alpha=122^{\circ}$. Note that the orientational data for $\gamma=10$ does not accurately reflect the microstructure due to difficulty in distinguishing the boundaries of white grains at such high strains.

orientation more favourable for slip. Depending on the sense and amount of spin, individual grains can completely change their crystallographic orientation. In the third microstructure column of Fig. 2, for example, one can see that the grain labelled A acquires a crystallographic orientation that is entirely new within the microfabric. Subgrain rotation recrystallization ('rotational recrystallization' of Poirier \& Guillope 1979) and microshearing occur preferentially in narrow zones between grains or groups of grains with different crystallographic orientations and vorticity rates (e.g. see axial ratio contours in Fig. 2, column 5 for areas surrounding diagonally hatched grains like grain B in column 3 of Fig. 2). The sense of microshearing along the steep boundaries of elongate grains is initially antithetic with respect to the bulk shear sense in the sample and resembles bookshelf or domino gliding in rotating, anisotropic aggregates (e.g. see Lloyd et al. 1992).

With strain beyond $\gamma=1$, dynamic recrystallization involves both progressive subgrain rotation and grain boundary migration (Drury \& Humphreys 1986, Drury \& Urai 1990). In addition, videotapes of the evolving 


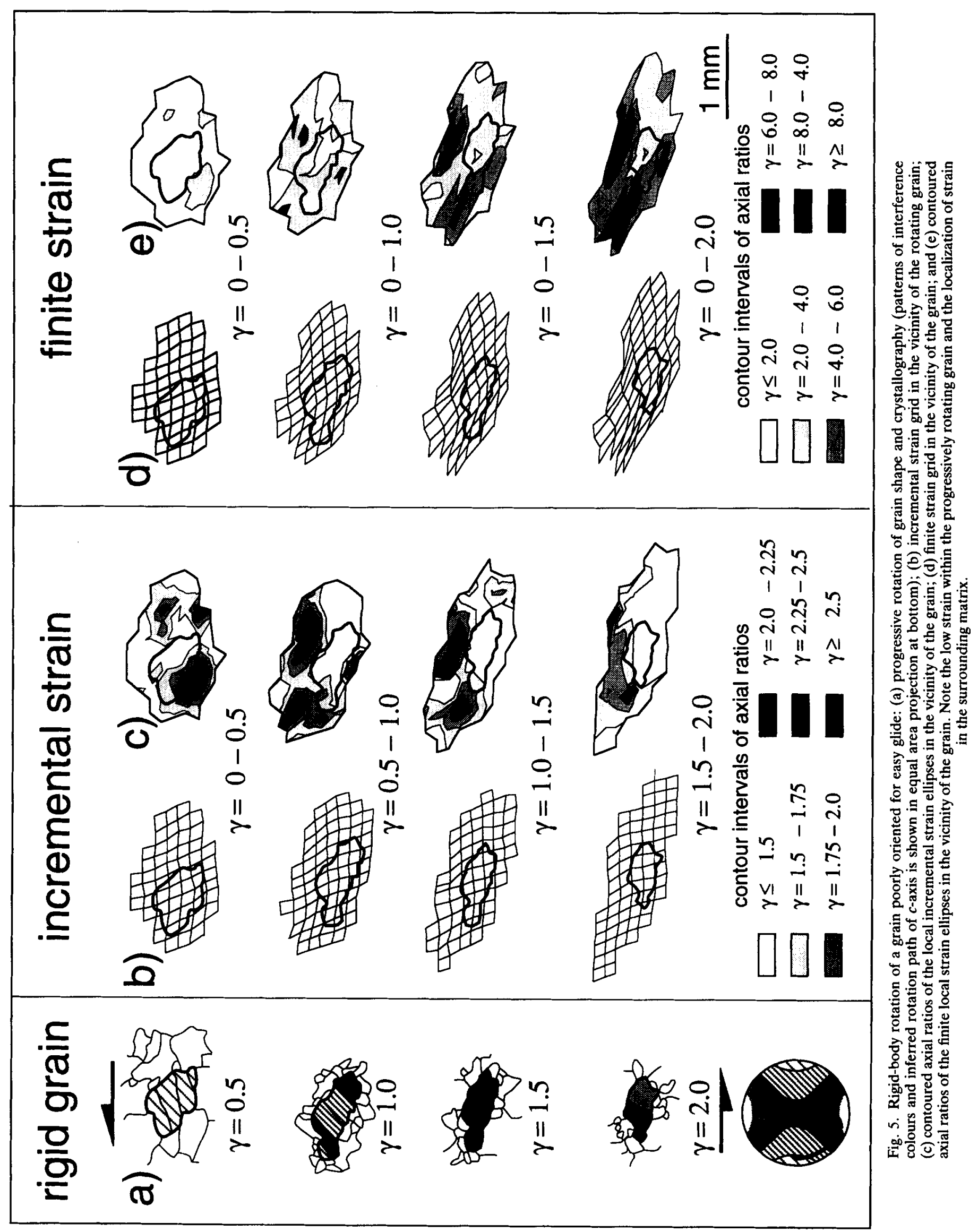




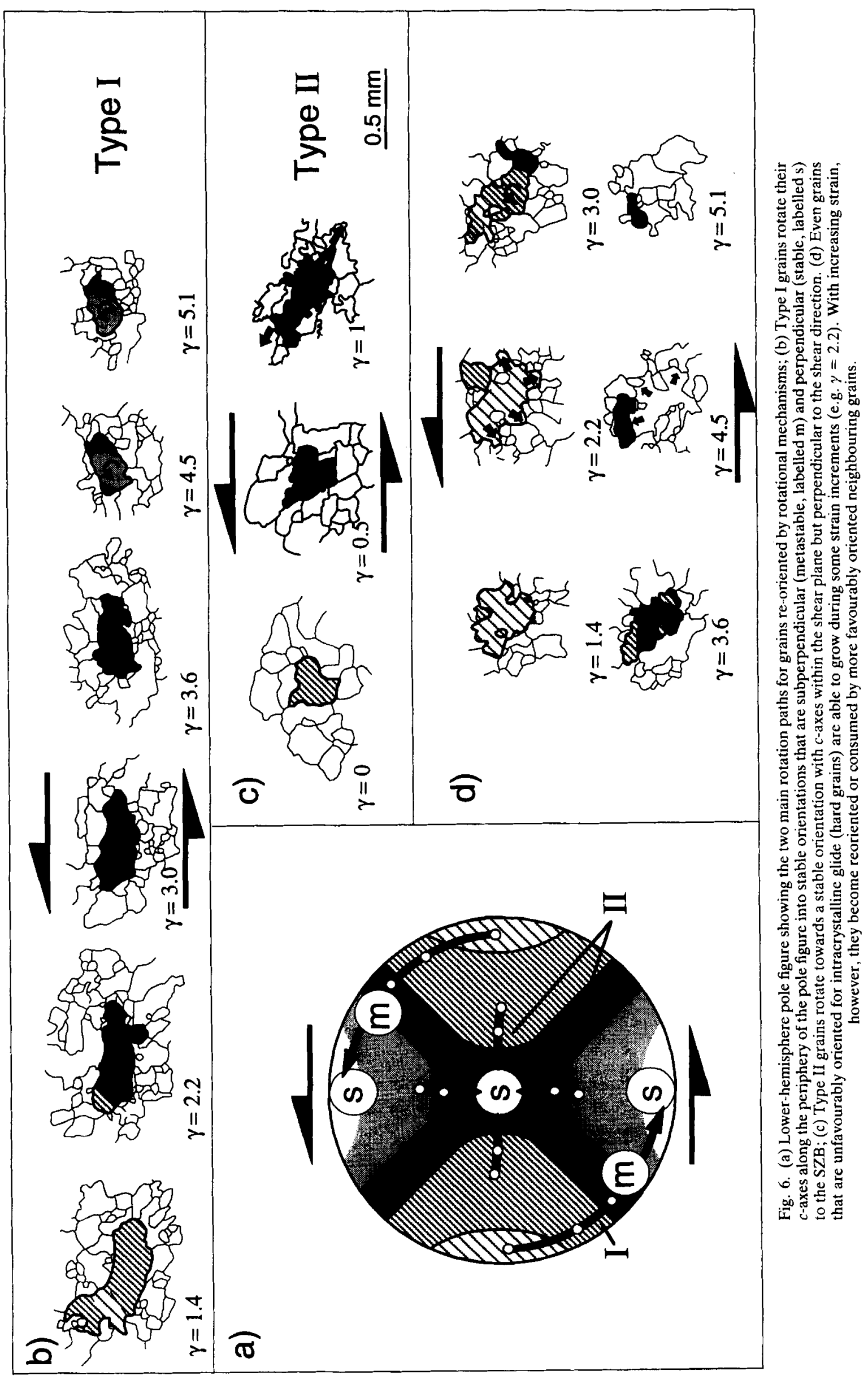



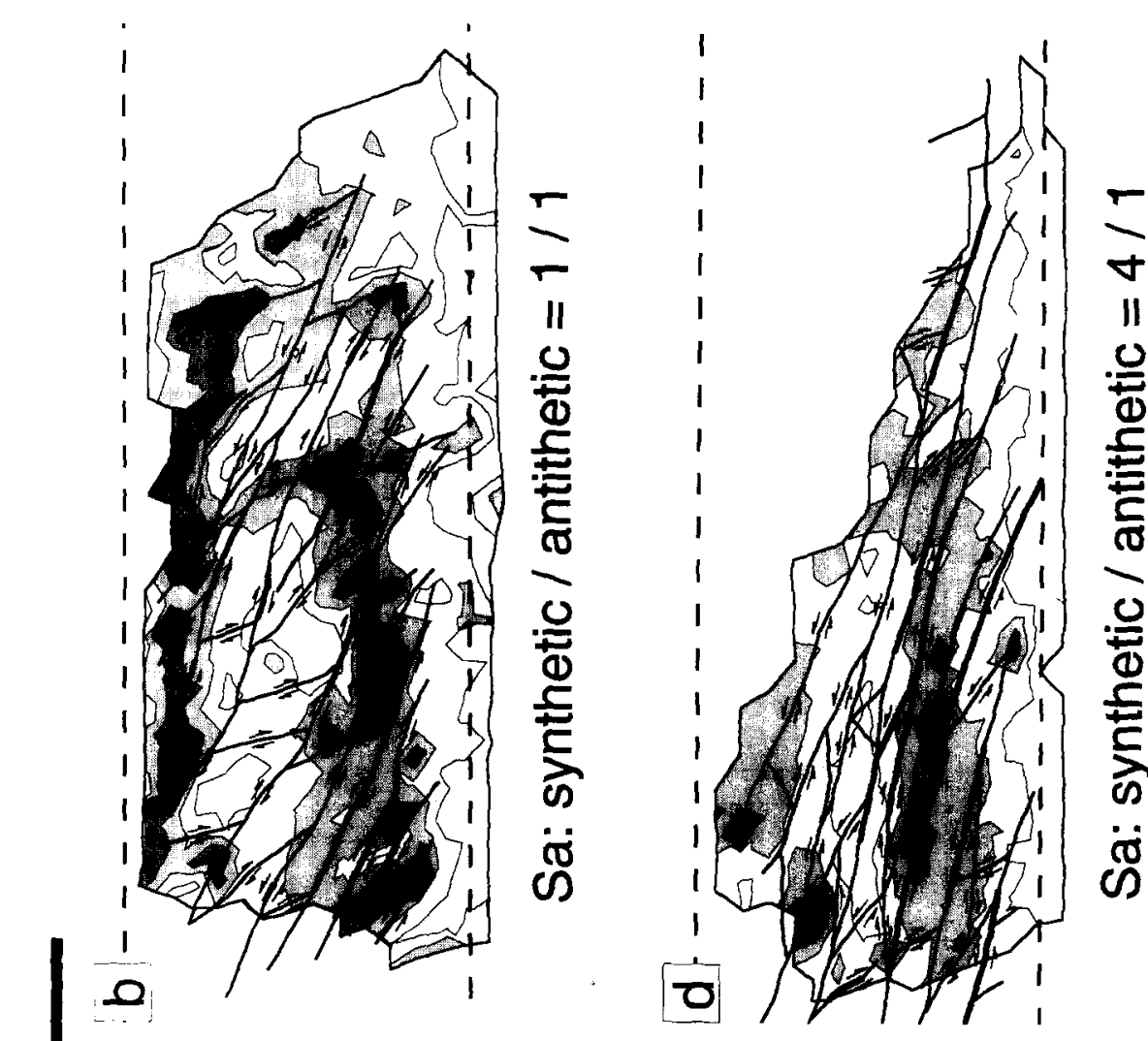

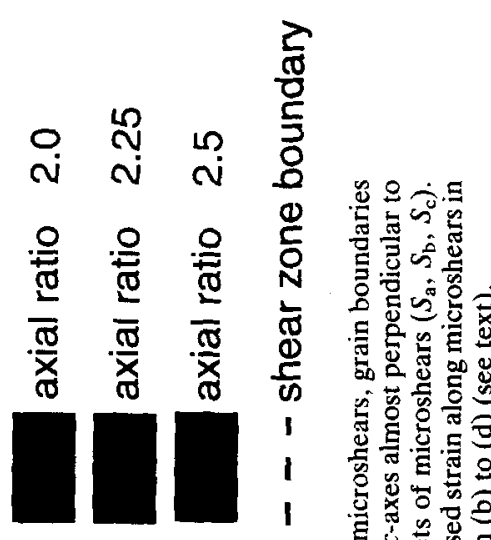

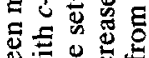

ஸ़

$\bar{v}-\leftarrow-\dot{2}$

은 은 윤 은 혼

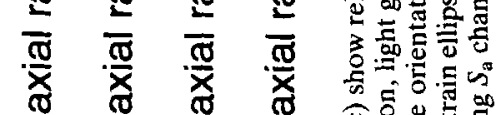

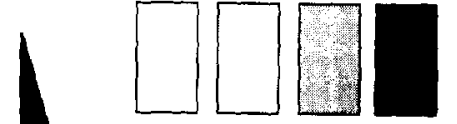

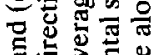

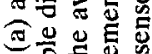

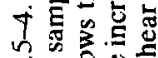

그음

II)

马용.

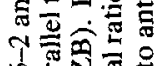

n

11 을

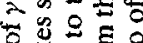

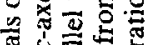

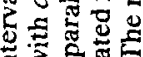

的政

สี

实苍

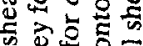

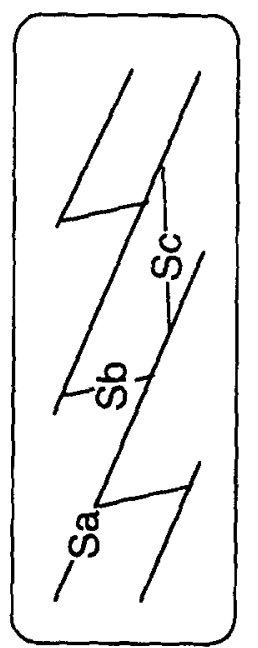

क

昰军

委

E

20응 95

글응

है형

要 영

文哥

듭요음

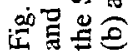
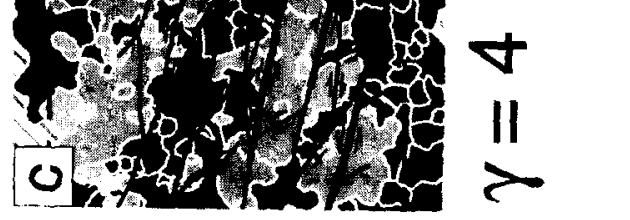


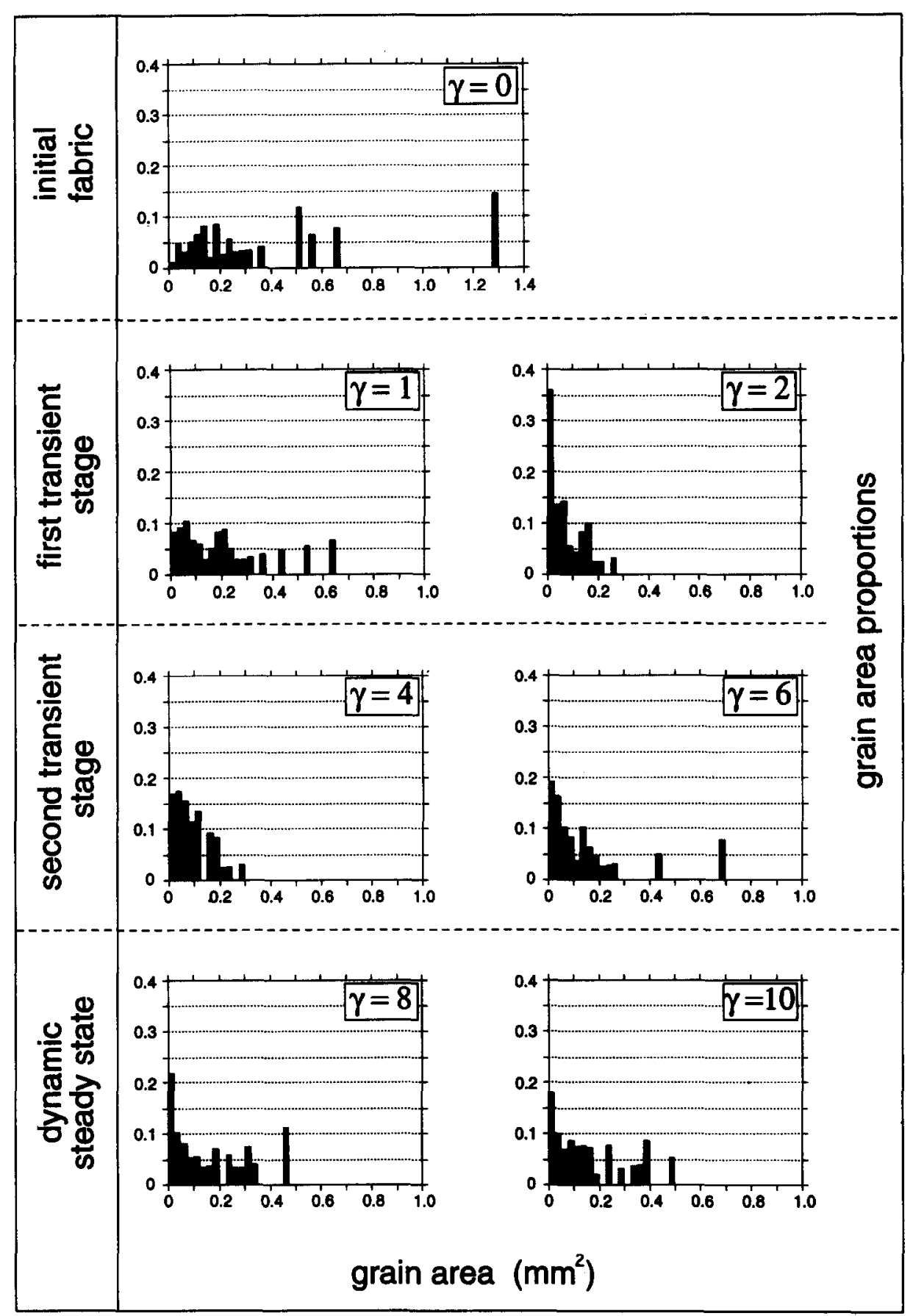

Fig. 8. Grain area (size) evolution with strain. Vertical axis: proportion of grains with a given area, horizontal axis: grain area in $\mathrm{mm}^{2}$. Note that the average grain size initially decreases up to a shear strain of $\gamma=2$, then increases and eventually stabilizes at shear strains of 8 and greater.

microstructure document the sudden appearance of tiny hexagonal grains along grain boundaries or within grains. The non-random crystallographic orientation of these newly nucleated grains suggests that they originated via bulging rather than classical nucleation (Drury \& Urai 1990, Urai et al. 1986). Initially, these grains grow very rapidly, but their growth rate decreases as they attain a size similar to that of optical subgrains. These newly nucleated grains then become elongate as they grow anisotropically in the direction of the instantaneous stretching axis. Although grain boundary migration recrystallization is active throughout this low strain stage, it is clearly subordinate to the aforementioned mechanisms.

The evolution of texture during this stage reflects primarily the activity of rotational mechanisms: lattice rotation involving intracrystalline glide-induced vorticity, rigid-body rotation (spin) and subgrain rotation recrystallization. By a shear strain of $y=1$, the $c$-axes in norcamphor form a weak cross-girdle pattern (Fig. 2, second column) with point maxima parallel to the $Y$ fabric direction and at high angles to the shear plane. The progressive strengthening of these maxima with strain ( $\gamma=4$ in second column of Fig. 2) involves 
complex strain paths for individual grains. For example, at least two types of rotational paths are inferred for the rigid grains based on changes in their interference colours (diagonally hatched and shaded grains in Fig. 6): Type I paths traverse the periphery of the pole diagram as some $c$-axes become oriented at high angles to the SZB (Fig. 6b). In contrast, grains with type II paths orient their $c$-axes within the shear plane but perpendicular to the shear direction (Fig. 6c). We cannot determine unequivocally the sense of rotation of the crystallography in these grains from changes in their interference colours alone. Based on recent texture analysis of experimentally sheared norcamphor with computer-integrated polarization microscopy (CIP, Panozzo \& Pauli 1993), however, we infer synthetic rotations of the crystallography with respect to the bulk vorticity of simple shearing (Fig. 6a). It is important to note that both the texture and the microstructure become increasingly domainal on the scale of the shear zone. We adopt the term 'domain' from Garcia Celma (1982) to refer to a cluster of grains with similar crystallographic and shape preferred orientations. The boundaries of these microfabric domains often coincide with microshear zones within the aggregate. Such microshear zones are marked by local changes in the trend of the deformed lines forming the incremental strain grids. By tracing along these zones of changing grid line trend and noting the deflection angle of the grid lines across such zones, we were able to map both the geometry and shear sense of the microshears onto the incremental strain grids and then superpose these maps on the corresponding microstructure (e.g. Fig. 7).

At a bulk finite shear strain of $\gamma=2$, the high strain zones surrounding less deformed grains or grain aggregates interconnect to form an anastomozing pattcrn (Figs. 7a \& b). Three different types of microshear zone are distinguished based on their orientation and kinematic history: (1) $S_{\mathrm{a}}$ microshears accommodate most of the strain and are oriented parallel to the long axis of the finite strain ellipsoid. Most of them initiate as discrete antithetic slip planes along steep grain boundaries (see above) before interconnecting and rotating progressively toward parallelism with the SZB. This rotation is associated with a switch in the shear sense along some of the $S_{\mathrm{a}}$ microshears, so that by $\gamma=2$ the ratio of synthetic to antithetic $S_{\mathrm{a}}$ microshears is approximately one. The strain-dependent lengthening of the $S_{\mathrm{a}}$ microshears as well as their decreased spacing (Fig. 7) reflects a component of pure shear extension parallel to the main axis of the finite strain ellipse during bulk simple shear. $S_{\text {a }}$ microshears are actually 'stretching faults' in the sense of Means (1989a); (2) $S_{\mathrm{b}}$ microshears are oriented more steeply with respect to the SZB than $S_{\mathrm{a}}$ microshears and accommodate predominantly antithetic shear; (3) $S_{\mathrm{c}}$ microshears are conjugate with respect to $S_{\mathrm{b}}$ microshears and accommodate predominantly synthetic shear (Fig. 7). Note that the $S_{\mathrm{a}}$ and $S_{\mathrm{b}}$ microshears in our experiments are closely related to Knipe and Law's (Knipe \& Law 1987) $S_{\mathrm{A}}$ and $S_{\mathrm{B}}$ directions observed in greenschist facies quartz mylonite (see their fig. 1).
Their terms $S_{\mathrm{A}}$ and $S_{\mathrm{B}}$ refer, respectively, to the macroscopic schistosity and the oblique alignment of dynamically recrystallized quartz grains, whereas our $S_{\mathrm{a}}$ and $S_{\mathrm{b}}$ surfaces represent rotating microshear zones that are active during most of the bulk kinematic history (see later discussion of natural mylonitic fabrics).

The progressive localization of strain is also associated with a reduction in the average grain size of the aggregate (Fig. 8). Ostensibly, this is due to the increased activity of both subgrain rotation recrystallization and the nucleation of very fine grains.

\section{Second transient stage}

In contrast to the first transient stage in which rotational mechanisms lead to marked changes in the microfabric, the second transient stage involves a predominance of grain-boundary migration recrystallization with a decrease in the activity of subgrain rotation recrystallization and a slightly increased activity of nucleation. The average grain size increases with respect to the size attained during the first stage (Fig. 8), an observation previously made in dynamically recrystallizing ice undergoing progressive simple shear (Wilson and Russell-Head 1982). Also, the domainal microfabric formed during the first stage becomes more pronounced. The rate at which the domains attain textural and microstructural homogeneity differs, however: dark domains in Fig. 2 form already during the first transient stage at about $\gamma=1$, whereas light domains develop during the second stage at $\gamma=4$. The development of the light domains in Fig. 2 involves a combination of grain elongation, grain boundary migration, and coalescence of smaller grains with similar crystallographic orientations (Fig. 9; see also Means \& Dong 1982). This is associated with an increase in the volume proportion of light grains (Figs. 2 and 10).

The progressive strengthening of the domainal microfabric above is closely related to the texture development in the second transient stage. Grains whose $c$-axes maxima are oriented either slightly oblique to the $Z$ fabric direction or parallel to the $Y$ fabric direction grow at the expense of grains with other $c$-axis orientations (see weakening of $c$-axis point maxima at a $45^{\circ}$ angle to the SZB in second column of Fig. 2). This coincides with a transition from the asymmetric cross girdle of the first transient stage to two point maxima in Fig. 2. The straight line connecting these point maxima is oblique with respect to the $S_{\mathrm{a}}$ microshears and the SZB. Straindependent strengthening of point maxima perpendicular to SZB have also been observed in octachloropropane (OCP) undergoing simple shear (Ree 1991) and in ice subjected to torsional shear (Bouchez \& Duval 1982).

The system of anastomozing microshear zones formed in the first stage rotates synthetically such that $S_{\mathrm{a}}$ microshears remain approximately parallel to the finite stretching axis (Figs. 7c \& d). In contrast to the first stage, however, the shear sense along most $S_{\text {a }}$ microshears is now synthetic with respect to the bulk shear 


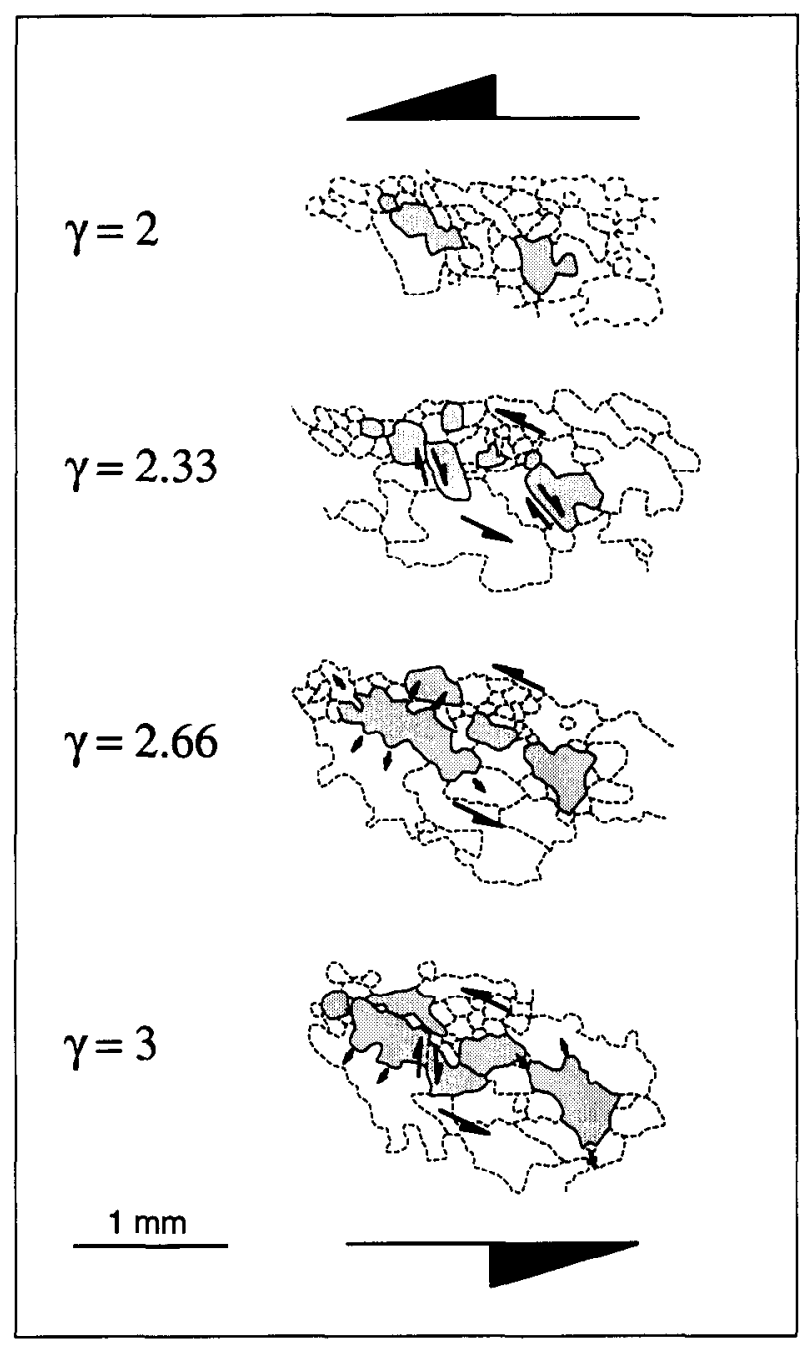

Fig. 9. Progressive domain growth with increasing shear strain. This involves a combination of microshearing and extensive grain boundary migration recrystallization leading to the coalescence of similarly oriented grains.

sense (Fig. 7d). This change in shear sense is attributed to the fact that $S_{\mathrm{a}}$ microshears have rotated synthetically from an average orientation accommodating pure shear into one favouring a greater component of simple shear. Both the $S_{\mathrm{b}}$ and the $S_{\mathrm{c}}$ microshears also rotate synthetically, but with a higher vorticity rate than do $S_{\mathrm{a}}$ microshears. Note in Fig. 7 that all three types of microshear occur both between and within grains or microfabric domains. In contrast to the first transient stage, therefore, the microfabric is not as obviously related to the strain partitioning. Where the microshears coincide with grain or domain boundaries, grain boundary migration recrystallization is inferred to accommodate some of the strain. The local shear sense along these boundaries can be inferred from the asymmetry of sheared and rotated grain boundary bulges (see Fig. 11, criteria of Drury \& Humphreys 1986, 1988). The inferred shear sense agrees with that obtained from offsets of the incremental deformation grid. Videotapes of the evolving microfabric show that grain boundary bulges are ephemeral and can grow across the microshears (Fig. 11). Where the microshears transect grains, the strain is accommodated via intracrystalline mechanisms, including progressive sub- grain rotation. This can result in the formation of elongate zones containing small grains. Interestingly, the area of the deformed gridline cells that define the microshears in Fig. 2 (fourth column) is smaller than that of the adjacent, less deformed parts of the sample. Together with the concentration of marker particles within the microshear zones, this observation suggests that significant volume loss involving syntectonic mass transfer of norcamphor out of the microshears has occurred. Similar phenomena have been observed along sheared grain boundaries in OCP (Ree 1994).

\section{Steady state}

The microfabric reaches steady state at a shear strain of about $\gamma=8$. Neither the texture nor the microstructure vary with strain on the scale of the entire sample (Figs. 2, 4, 8 and 10), but the crystallographic orientation, shape, size, and position of individual grains and grain aggregates within the sample change continuously. The most intriguing aspect of steady state, however, is that the dynamic microfabric does not as readily reflect the pattern of strain partitioning. Only by superposing the microfabric images on detailed photographs of the sheared trains of tiny corundum marker particles and then re-examining the norcamphor grain boundaries in detail were we finally able to establish a relationship. Grain boundary migration recrystallization is the dominant grain-scale process during this stage, but is accompanied by subordinate activity of subgrain rotation recrystallization and nucleation. Furthermore, a significant influence of glide-induced vorticity is inferred from the persistence of a strong texture. The relative activity of these mechanisms at $\gamma \geqslant 8$ is invariant with strain, as inferred from the arcal distribution of their diagnostic microstructures within the deforming samples (see Knipe 1989, Schmid and Handy 1991 for a listing of criteria used to identify deformation mechanisms). This has led us to coin the term 'active mechanism assemblage' to describe the combination of deformation mechanisms and related processes that affect microfabric evolution.

The steady-state microstructure in Fig. 2 (third column) is domainal, but these domains contain a much greater volume proportion of light grains than in the transient domainal microfabrics described above. The proportion of light to dark grains remains constant with shear strains greater than $\gamma=8$ (Fig. 10). The light grains correspond to the $c$-axis maxima perpendicular to the shear plane, whereas the dark grains have maxima parallel to the $Y$ fabric direction. We interpret both of these crystallographic orientations to represent easy glide alignment of the grains' basal and prism slip systcms (see following discussion). The stcady-state texture comprises two $c$-axis point maxima whose skeletal outline defines an oblique alignment (Fig. 2, bottom of second column).

At first glance, the microfabric appears unrelated to the pattern of microshear zones because the $S_{\mathrm{a}}$ microshears transect grains without offsetting their grain 


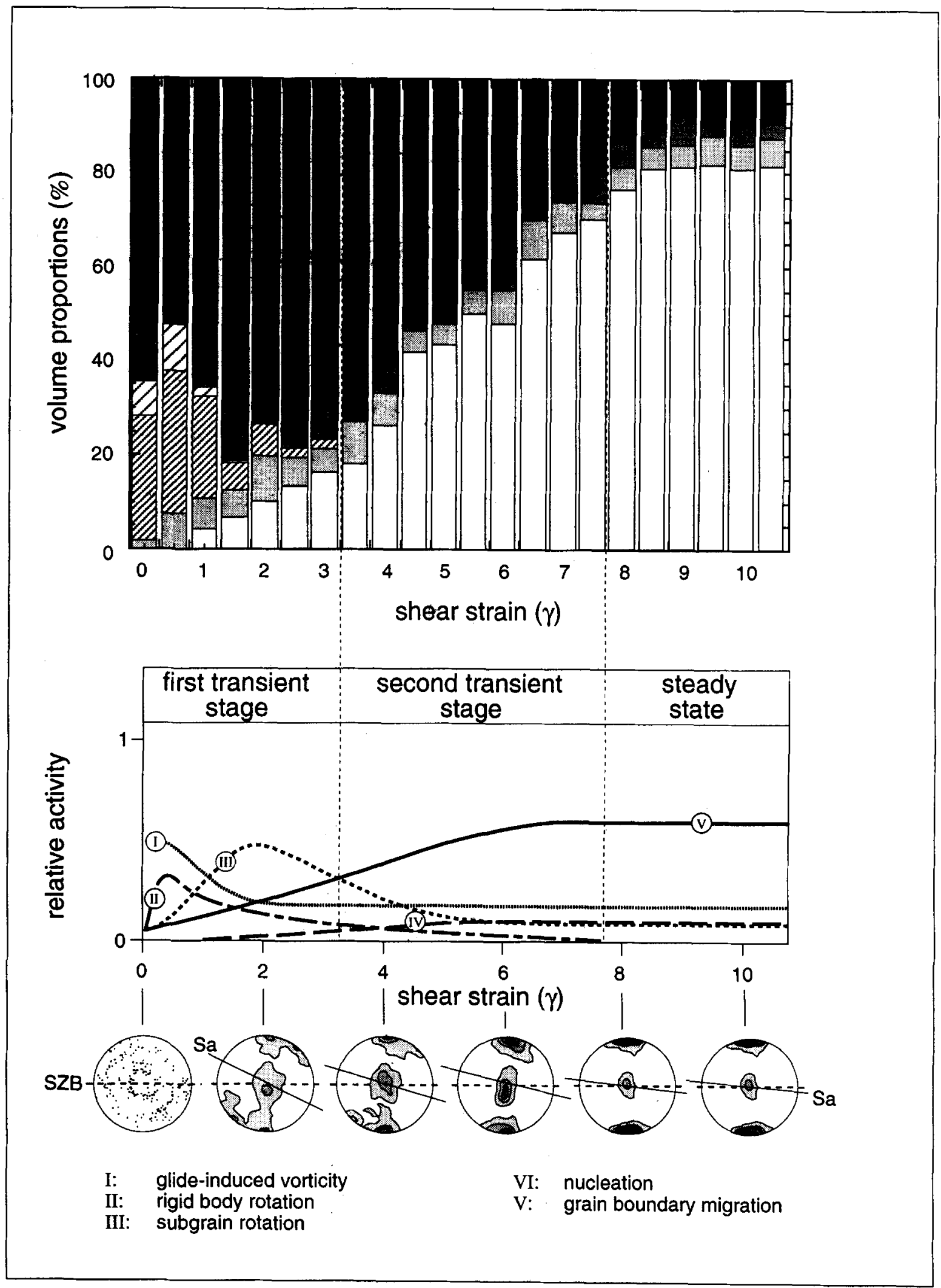

Fig. 10. Evolution in the volume proportions of variously oriented grains (top), relative mechanism activities (middle) and $c$-axes patterns (bottom). Grey shades and hatching identical to those used in Fig. 2. See text for explanation.

boundaries. On closer examination, however, $S_{\mathrm{a}}$ microshears within light grains correspond to subgrain boundaries that are oriented subparallel to the SZB (last two pictures of fifth column in Fig. 2). A second set of subgrain boundaries is subvertically oriented, i.e. sub- perpendicular to the SZB. The slight difference in crystallographic orientation across these subvertical boundaries reflects minor kinking and rotation in response to slip on the subgrains' basal planes parallel to $S_{\mathrm{a}}$ and subparallel to the SZB. In contrast to $S_{\mathrm{a}}$ microshears, $S_{\mathrm{b}}$ 


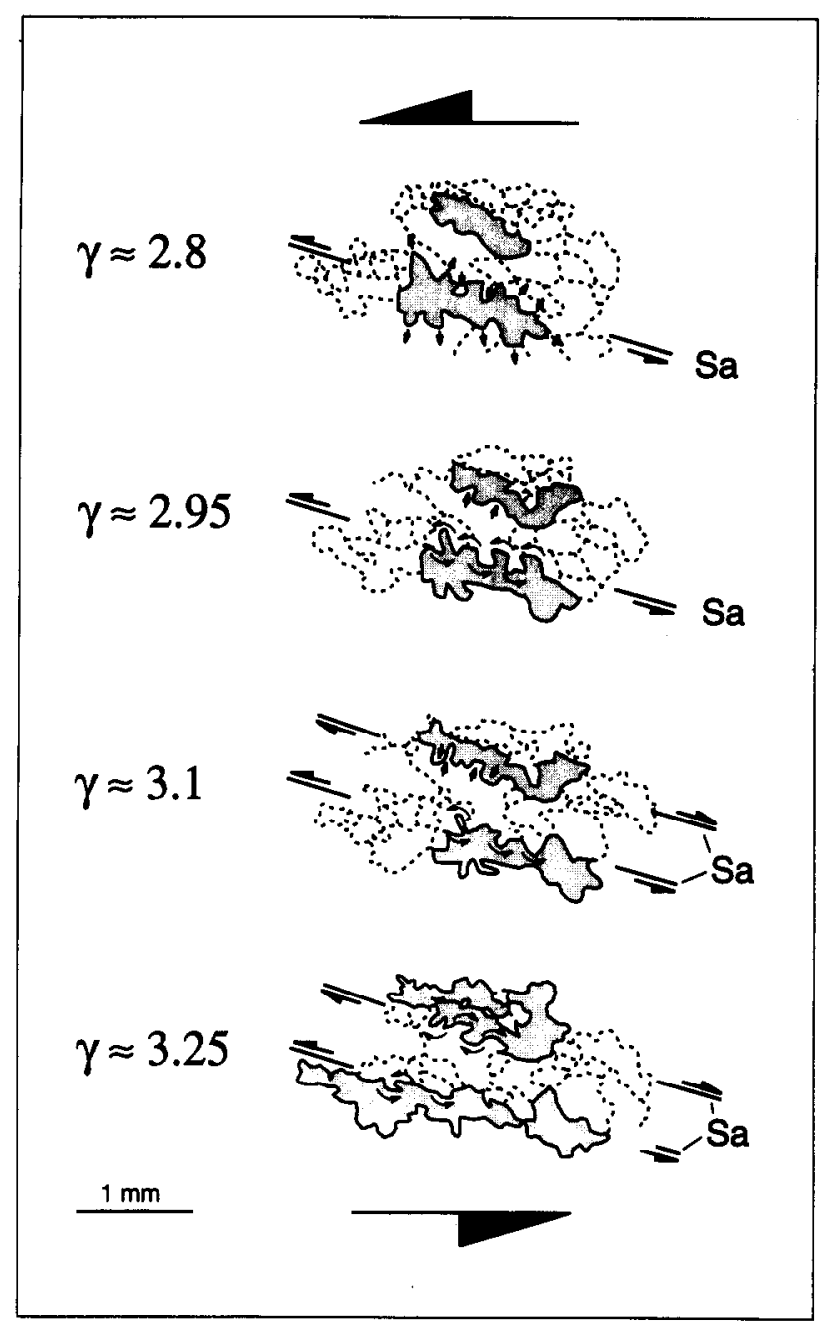

Fig. 11. Bulges initially grow subperpendicular to the average grain boundary orientation. With progressive strain, they become asymmetrical and lean in the direction of shear along $S_{\mathrm{a}}$ microshears.

and $S_{\mathrm{c}}$ microshears coincide with small domains of dark grains that nucleate and grow along the slanted boundaries of elongate light grains (Fig. 2). These dark domains are situated between, and rotate synthetically towards, the $S_{\mathrm{a}}$ microshears. Therefore, we interpret the dark domains to comprise grains whose slip systems are oriented for easy glide within the $S_{\mathrm{b}}$ and $S_{\mathrm{c}}$ microshear zones. When the angle between $S_{\mathrm{a}}$ and $S_{\mathrm{b}}$ microshears becomes smaller than $25-30^{\circ}$, light grains consume dark grains along the rotated $S_{\mathrm{b}}$ planes by grain-boundary migration recrystallization. These observations support two conclusions: First, the slip systems of light grains are favoured over those of dark grains to accommodate simple shear parallel to $S_{\mathrm{a}}$ microshears and subparallel to the SZB. A cyclic history of nucleation, growth, and consumption is also observed for the light grains. Second, $S_{\mathrm{b}}$ and $S_{\mathrm{c}}$ microshears nucleate continuously at angles to the SZB and rotate synthctically into an $S_{\mathrm{a}}$ orientation. However, $S_{\mathrm{b}}$ and $S_{\mathrm{c}}$ microshears are only recognizable as such when dark grains are present.

To summarize this section, the development of a steady-state microfabric in norcamphor is characterized by increasing strain heterogeneity and the changing relative effect on the microfabric of several grain-scale mechanisms. Steady-state deformation is highly heterogeneous and involves a constant relative activity of such mechanisms. The interaction of these mechanisms maintains a dynamic equilibrium between microfabric modification and conservation. In this way, a texture and microstructure are produced that are invariant with strain on the scale of the shear zone.

\section{A COMPARISON OF MICROFABRICS IN NORCAMPHOR AND NATURAL QUARTZ MYLONITE}

How realistic are our experimental norcamphor microfabrics? To answer this question, we sampled a mylonitic quartz lens from the Monte Rosa augengneiss along the Insubric line in northern Italy (Fig. 12). The augengneiss is an upper greenschist to lower amphibolite facies mylonite with a steeply NNW-dipping mineral stretching lineation (Kruhl \& Voll 1976). The mylonite comes from the northern part of the Insubric mylonite belt that accommodated Tertiary uplift and backthrusting of the hot Lepontine nappes onto the cool, southern Alpine Ivrea zone (Schmid et al. 1987).

Comparing Fig. 12 with Figs. 2, 4 and 8 reveals many similarities between norcamphor and quartz microfabrics. The most striking similarity is the occurrence of a pronounced SPO of the dynamically recrystallized grains oblique to the shear zone boundary. The long axes of most quartz grains form at $50-60^{\circ}$ to the schistosity (Fig. 12a). The schistosity and the boundaries of the elongate grains defining the SPO correspond, respectively, to the $S_{\mathrm{a}}$ and $S_{\mathrm{b}}$ microshears in norcamphor (Figs. $7 \mathrm{a} \& \mathrm{c}$ ). A smaller number of quartz grains have boundaries oriented at angles of betwecn $135^{\circ}$ and $160^{\circ}$ to the schistosity. These grain boundaries delineate a third planar fabric element which we have already identified as $S_{\mathrm{c}}$ microshears in norcamphor. In both quartz and norcamphor, asymmetrical bulges along straight segments of grain boundaries yield shear senses that are consistent with predominantly antithetic and synthetic shear, respectively, along the $S_{\mathrm{b}}$ and $S_{\mathrm{c}}$ microshears (compare Figs. 12b \& c with Fig. 11). The strong resemblance of quartz and norcamphor microstructures is reflected in the almost identical particle and surface preferred orientation patterns in Figs. 12h \& i (quartz) and Fig. 4 (norcamphor at $\gamma=8$ ), as well as in the similar grain size distributions (Fig. 12g for quartz, Fig. 8 for norcamphor at $\gamma=8$ ).

The predominance of syntectonic grain boundary migration recrystallization in quartz and norcamphor reflects the relatively high homologous temperature of mylonitization. A small population of fine, equiaxed grains betrays the limited activity of subgrain rotation recrystallization under these conditions. Small hexagonal strains occurring locally along the boundaries of large quartz grains may be newly nucleated, just like those observed in the norcamphor experiments (compare Fig. 12d with micrograph in lower right-hand corner of Fig. 2). 
The $c$-axis texture of norcamphor is similar, but not identical to that of naturally deformed quartz. The oblique single $c$-axis girdle for quartz in Fig. $12 \mathrm{f}$ has its approximate counterpart texture in norcamphor deformed to a shear strain of $\gamma=8$ (Fig. 2). In both quartz and norcamphor, the asymmetry of the $c$-axis pattern with respect to the main foliation $\left(S_{\mathrm{a}}\right)$ as well as the angular relationship between $S_{\mathrm{a}}$ and $S_{\mathrm{b}}$ planes are consistent with the bulk sense of shear in the samples (sinistral in Figs. 2 and 12; criteria of Simpson \& Schmid 1983, Law 1990). However, the relative strength and some positions of the $c$-axis maxima in norcamphor differ from those in quartz: in norcamphor, for example, point maxima develop at the periphery of the pole figures (Fig. 2), whereas in the quartz studied here, $c$ axes tend to concentrate around the $Y$ fabric direction (Fig. 12f).

These textural differences are interpreted to reflect differences in the relative activity of the various slip systems in norcamphor and quartz. By analogy with complete textural analyses of naturally deformed quartz (Schmid \& Casey 1986), the strong $Y$-maximum for quartz in Fig. 12f can be related to a strong activity of prism $\{m\}$ in the $\langle a\rangle$ direction. Likewise, the submaximum towards the lower margin of the pole figure in Fig. $12 \mathrm{f}$ may be attributed to subordinate glide on the acute rhombs $\left\{\pi\right.$ or $\left.\pi^{\prime}\right\}$ in the $\langle a\rangle$ direction (Law et al. 1990). An interpretation of the norcamphor textures based on the preferred orientation of readily identifiable slip systems is necessarily tentative pending a better characterization of norcamphor's crystallography. Nevertheless, the development of point maxima at the periphery and centre of the pole figures in Fig. 2 suggests that glide in norcamphor occurred preferentially on the basal and prism planes. The rhomb systems in norcamphor were not active, as inferred from the absence of the corresponding $c$-axis submaxima observed above in quartz.

In sum, the observations above indicate that despite differences in the material properties of norcamphor and quartz, the two substances exhibit similar microstructures, deformation mechanisms and textures. Norcamphor is indeed a good quartz analogue material and can therefore be used to draw inferences of a more general nature on microfabric evolution in quartz.

\section{DISCUSSION}

The norcamphor experiments show that three different, but closely related phenomena characterize the evolution towards a steady state (i.e. strain-invariant) microfabric: (1) strain-dependent variations in the relative influence of grain-scale mechanisms on the microfabric; (2) heterogeneity of strain on several scales of observation; and (3) a textural transition from symmetrical $c$-axis cross-girdle patterns to a stable point maxima pattern whose outline is slightly oblique to the SZB.

Figure 10 qualitatively depicts the changes in the activity or relative effect on the microfabric of the five grain-scale mechanisms identified above. The combination of these mechanisms affects the way in which strain partitions and textures evolve. During the first transient stage, glide planes undergo wholesale rotation via intracrystalline glide-induced vorticity, rigid-body rotation (spin) and subgrain rotation recrystallization. In the second transient stage, grain boundary migration recrystallization predominates and facilitates the selective growth of grains that are favourably oriented for slip. At steady state, the relative activity of the mechanisms becomes invariant with strain and reflects the ambient temperature and strain rate of deformation. This is in qualitative agreement with results from the experimental coaxial shearing of quartzite (Hirth \& Tullis 1992, Gleason et al. 1993) showing that texture evolution is closely linked to several grain-scale mechanisms whose relative activity at steady state is a function of the deformational conditions. In particular, the predominance of grain boundary microshearing and grain boundary migration recrystallization in norcamphor has also been described by Lister \& Dornsiepen (1982, their fig. 9) for mylonitic quartz coaxially sheared under granulite facies conditions. The experimental evidence for changing relative activities of several grain-scale mechanisms contrasts with the simple assumptions commonly made in modelling textural evolution that only one or two mechanisms effect lattice rotation and that the mechanism assemblage prior to the attainment of steady state is invariant with strain (see brief review in the Introduction).

Strain localizes within three independent sets of microshears $\left(S_{\mathrm{a}}, S_{\mathrm{b}}\right.$ and $\left.S_{\mathrm{c}}\right)$ during the first transient stage of deformation and remains heterogeneous, even to very high strains at steady state. The operation of three independent shear systems fulfils von Mise's criterion for strain compatibility during plane strain simple shear of the norcamphor aggregate. As mentioned above, there is an intimate relationship between strain localization and texture evolution: during the transient stages, $S_{\mathrm{a}}$ microshears form subnormal to the SZB and rotate synthetically with respect to both the SZB and the global $\sigma_{1}$ orientation. In rotating, they undergo a switch from predominantly antithetic to synthetic shear while accommodating a variably strong component of pure shear extension parallel to their length. The configuration of microshears and inferred orientation of the glide planes in norcamphor at this stage is shown schematically in Fig. 13a. The cross girdle $c$-axis outline is symmetrical with respect to the $S_{\mathrm{a}}$ microshears and may reflect duplex glide on a conjugate pair of basal planes in norcamphor. Together with the conjugate configuration of the $S_{\mathrm{b}}$ and $S_{\mathrm{c}}$ microshears with respect to the $S_{\mathrm{a}}$ surfaces, this facilitates stretching of the material between the $S_{\mathrm{a}}$ microshears parallel to the long axis of the finite strain ellipse (Fig. 13a). Thus, at low strains the bulk texture of the sample primarily manifcsts pure shear along the $S_{\text {a }}$ planes with extension subparallel to the long axis of the finite strain ellipsoid, rather than bulk simple shear parallel to the SZB. With continued deformation, the $S_{\text {a }}$ planes rotate into parallelism with 


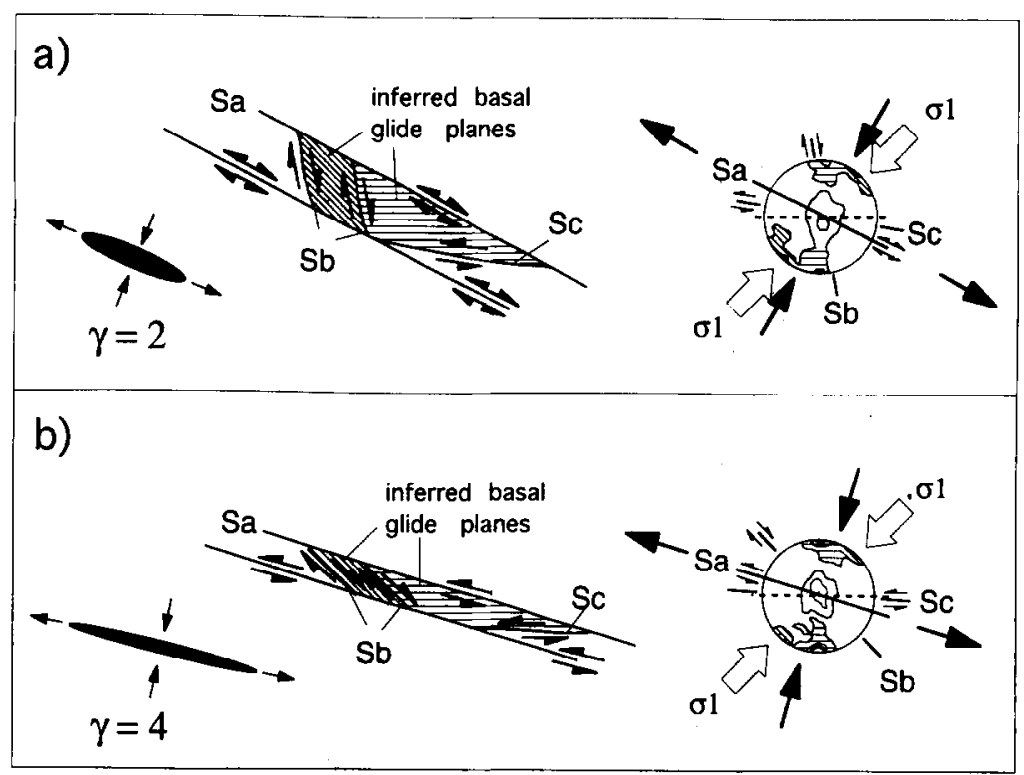

Fig. 13. Relationship of intra- and intercrystalline shearing to norcamphor $c$-axis texture at the transition from first to the second transient stages during simple shearing. Urientation of microshears $S_{\mathrm{a}}, S_{\mathrm{b}}$ and $S_{\mathrm{c}}$, inferred basal glide planes (diagonal hatching) and lower hemisphere equal area projection of norcamphor $c$-axes at shear strains of (a) $\gamma=2$ and (b) $\gamma=4$. Finite strain ellipses at lower left for comparison. Big black arrows indicate the direction of the finite strain and stress axes. See text for discussion.

the SZB and accommodate predominantly synthetic shear (Fig. 13b). This coincides with the textural transition from a symmetrical cross-girdle to a stable oblique point maxima configuration at steady state. This transition reflects the increased component of simple shear localized along the $S_{\mathrm{a}}$ and $S_{\mathrm{b}}$ microshears. Norcamphor's basal glide planes are oriented subparallel to the $S_{\mathrm{a}}$ microshears, whereas its prisms align for slip subparallel to the $S_{\mathrm{b}}$ and $S_{\mathrm{c}}$ microshears. At even higher shear strains, we infer that shearing along the $S_{\mathrm{a}}$ microshears decreases as strain is increasingly accommodated by intracrystalline slip on basal glide planes oriented subparallel to the SZB. This inference remains tentative in the absence of strain grids for microstructures at $\gamma \geqslant 8$. At the time of this writing, we are checking this inference by calculating incremental strain grids for norcamphor samples deformed to very high shear strains.

The three sets of microshears in our norcamphor samples appear to fulfil similar kinematic roles as Platt's (1984) main foliation $(S)$ and conjugate extensional crenulation cleavages (ecc1, ecc2): bulk simple shear is partitioned into slip along $S$, while coaxial stretching of the whole rock parallel to and between $S$ surfaces is accommodated by the simultaneous activity of eccl and ecc2. Platt's $S$ surfaces correspond to our $S_{\mathrm{a}}$ microshears whereas his ecc1 and ecc2 are similar to our $S_{\mathrm{b}}$ and $S_{\mathrm{c}}$ microshears. Thus, in both Platt's model and our experiments, flow within the shear zone departs from progressive simple shear. In Platt's model, however, the extensional crenulations are believed to form during late stages of ductile flow, whereas the $S_{\mathrm{b}}$ and $S_{\mathrm{c}}$ microshears in our norcamphor experiments already appear after a few strain increments $(\gamma=1.5)$. Also, our $S_{\mathrm{b}}$ and $S_{\mathrm{c}}$ microshears are not symmetrically disposed with respect to $S_{\mathrm{a}}$ as predicted by Platt for his ecc1 and ecc 2 surfaces. This may reflect the fact that the material between the rotating $S_{\text {a }}$ microshears undergoes a component of simple shearing while being flattened. Interestingly, the domainal microfabric in our norcamphor experiments at shear strains greater than 2 behaves in a way similar to that predicted by the twinned fibre domain model of Cobbold \& Gapais (1986). Rotation of slip planes during bulk simple shear involves a combination of localized pure and simple shear, respectively, normal and parallel to the domain boundaries (their shearing modes 1 and 2 , see their fig. 3). Domain boundaries migrate laterally, facilitating the growth of domains with slip planes oriented subparallel to the shearing plane at the expense of domains with poorly oriented (locked) planes. Eventually, this leads to strong, oblique preferred orientation of slip lines (see fig. 4 in Cobbold \& Gapais 1986).

At this point, we should emphasize that the transition in norcamphor from a symmetrical cross-girdle pattern to an oblique point maxima pattern occurs during plane strain simple shear and does not reflect a change in the bulk vorticity number during the experiment. Our result corroborates previous work in naturally and experimentally deformed ice (Hudleston 1978, Bouchez \& Duval 1982) and naturally deformed quartzite (e.g. Carreras et al. 1977, Carreras \& Garcia Celma 1982) indicating that this texture transition is accompanied by grain boundary migration recrystallization and occurs at shear strains ranging from $\gamma=1$ to 3 . Note, however, that the explanation offered above for the straindependent texture transition in norcamphor does not preclude the possibility that the same transition in naturally deformed quartz can also reflect an increase in the vorticity number during shearing (see fig. 14 in Schmid \& Casey 1986, Discussion in Schmid 1994).

One of the major points to cmerge from this study is that the steady state mechanism assemblage shown in Fig. 10 preserves a stable end-orientation of active glide 
planes that are oriented for easy glide. The term 'easy glide' refers to slip on a glide plane that has a low critical resolved shear stress and is conveniently oriented for maximum resolved shear stress in the direction of slip (e.g. Schmid 1994). At steady state in norcamphor, a large volume proportion of grains have their basal planes oriented for easy glide subparallel to the $S_{\mathrm{a}}$ microshears, whereas a small proportion of grains align their prisms for slip subparallel to the $S_{\mathrm{b}}$ and $S_{\mathrm{c}}$ microshears (pole figure in Fig. 10). The preservation of these two preferred orientations is a dynamic, cyclical process involving the nucleation and/or growth, rotation, and consumption of grains and groups of grains (see Fueten et al. 1991). Lister \& Snoke (1984) aptly refer to this process as a 'resetting of the finite strain clock' because the microstructure only records small intervals of the finite strain history before repeatedly reverting to a fresh, lower strain configuration.

Our study also offers insight into why some texture models based on the TBH (Lister et al. 1978) and VPSC (Wenk et al. 1989) theories have been unable to produce realistic textures for quartzite undergoing simple shear. These models assume that deformation involves solely intracrystalline glide-induced vorticity of the active slip planes, leading to a pulsating 'stop and go' rotation of the active glide systems through the easy glide orientations. The norcamphor experiments reveal that although such rotation does occur at steady state (e.g. see kinking of basal planes parallel to $S_{\mathrm{a}}$ in Fig. 2), grain boundary migration recrystallization selectively eliminates grains that rotate out of an easy glide orientation (i.e. into an orientation with a lower resolved shear stress). This supports arguments recently reviewed by Schmid (1994) in favour of a stable end orientation in the presence of dynamic recrystallization. Unless algorithms for texture-preserving mechanisms like nucleation and syntectonic grain boundary migration are incorporated into the models (e.g. Jessell 1988, Jessell \& Lister 1990), no stable end orientations can be predicted. In this context, it is interesting to note that our experimental textures support Jessell \& Lister's (1990) model predictions that grains with a high resolved shear stress (sometimes referred to as 'soft' grains) grow at the expense of 'hard' grains with a lower resolved shear stress. The similarity between our norcamphor experiments and the TBH-dynamic recrystallization models of Jessell \& Lister (1990) may be superficial, however, because of the different ways in which strain compatibility is maintained within deforming grain aggregates. In the Jessell-Lister model, dynamic recrystallization is the sole mechanism for eliminating poorly oriented, hard grains within a homogeneously deforming aggregate. If the computer runs were taken to very high shear strains, this would lead to continuous, unchecked grain growth and ultimately result in the survival of only a single crystal. In contrast, the norcamphor experiments point to the importance of rigid-body rotation, intergranular microshearing and cyclical grain-nucleation, -growth and -consumption in accommodating heterogeneous strain within the aggregate. Perhaps this discrepancy in maintaining compatibility explains why the $c$-axis point maxima in the transient stages of our norcamphor experiments rotate slightly with respect to the SZB whereas Jessell \& Lister's (1990) model $c$-axis textures do not (compare Fig. 2 with their fig. 2a).

Our interpretation that soft norcamphor grains ultimately grow at the expense of hard grains apparently contradicts arguments advanced by Gleason et al. (1993) for the favoured growth of hard grains in quartzite subjected to pure shear strains of $30 \%$. Although we also noted the growth of hard norcamphor grains at low to intermediate shear strains (see Fig. 6d at $\gamma=2.2$ ), such grains are eventually either consumed by their softer neighbours or themselves become soft as they rotate into an easy glide orientation. Thus, hard grain growth as reported in Gleason et al. (1993) may be a transient phenomenon restricted to lower strains.

Finally, our study indicates that the concept of a steady-state microfabric as originally defined by Means (1981) is strongly time- and scale-dependent. Not all aspects of the microfabric become strain-invariant simultaneously. For example, a pronounced SPO is established by a shear strain of $\gamma=2$, whereas grain size and texture only stabilize after a shear strain of $\gamma=8$ (Figs. 8 and 10). Moreover, steady state deformation is heterogeneous on all scales, even though this heterogeneity is not obviously manifested in the microstructure. Possibly, the development of microshears on the supragranular scale reflects strain incompatibilities that arise from the activity of only two independent glide systems during plane strain simple shear of norcamphor. Thus, incompatibility stemming from an insufficient number of independent slip systems on one scale may effect heterogeneous strain on another (in this case, larger) scale.

\section{SYNTHESIS AND GEOLOGICAL IMPLICATIONS}

Figure 14 synthesizes the microfabric evolution to steady state in norcamphor and quartz. During a first transient stage, rotation of the intracrystalline glide planes via shear-induced lattice rotation, rigid-body rotation and subgrain rotation recrystallization is accommodated by localized deformation along three sets of interconnected microshears. Both intracrystalline glide and supragranular microshearing accommodate localized, pure shear extension parallel to the long axis of the finite strain ellipse. Consequently, a cross-girdle $c$-axis texture develops symmetrically to the anastomosing $S_{\text {a }}$ microshears. Progressive rotation of the microshears during a second transient stage leads to an increase in the simple shear component on the $S_{\mathrm{a}}$ microshears. Grain boundary migration recrystallization favours the survival of grains with slip systems oriented for easy glide subparallel to the microshears. This is associated with a textural transition towards a stable oblique single girdle pattern. This textural end-orientation is preserved by the cyclic nuclcation, growth and consumption of grains associated with the continuous rotation of microshears (bottom of Fig. 14). It is this cyclicity that characterizes a dynamic, 


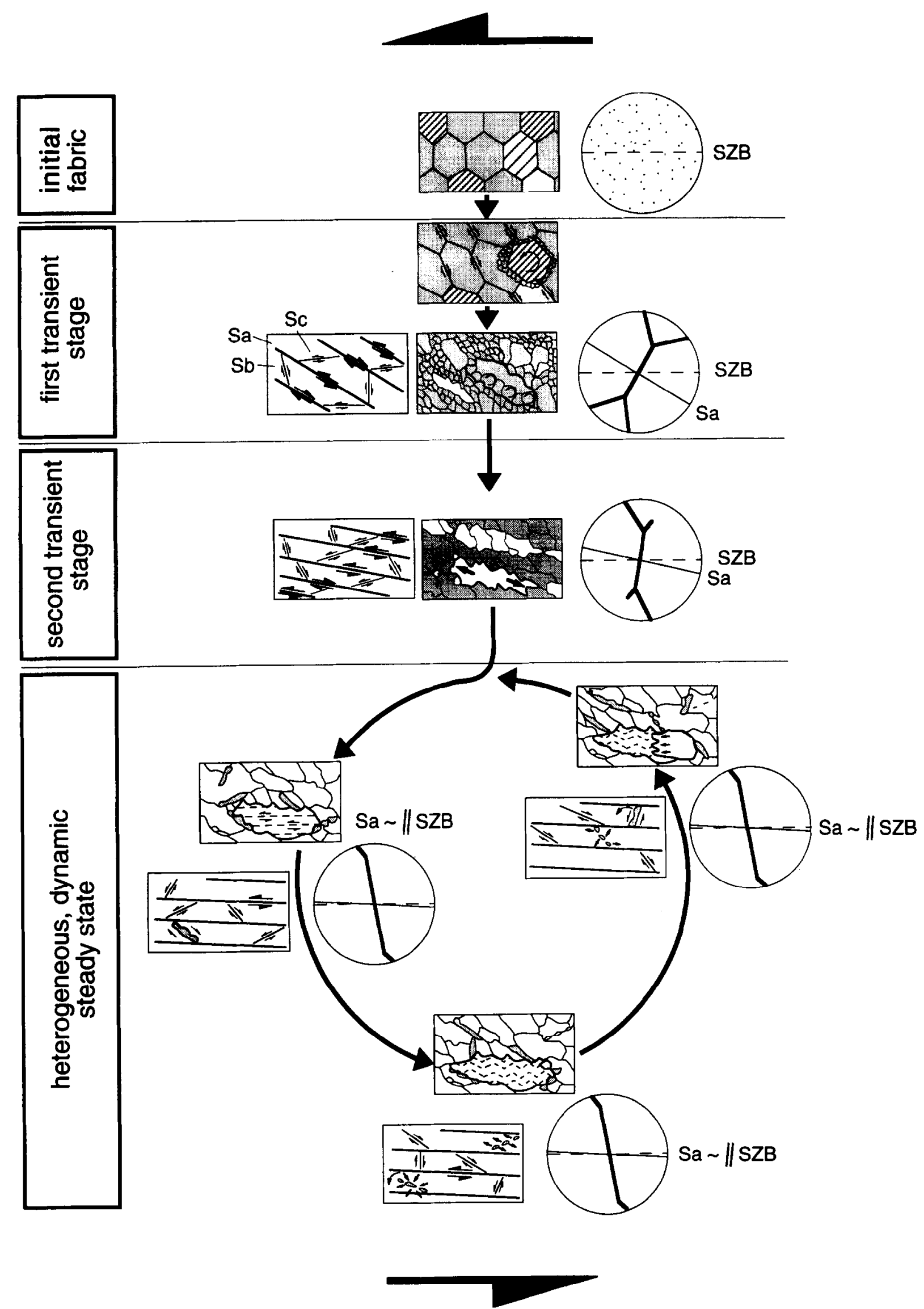

Fig. 14. Generalized, schematic microfabric evolution in a mylonite deforming at high homologous temperature (see text for explanation). 
heterogeneous steady state microfabric (e.g. Knipe \& Law 1987, Fueten et al. 1991).

Our study has several interesting consequences for the kinematic interpretation of microfabrics in quartz mylonite. (1) At low strains, the texture manifests the smallscale kinematics of heterogeneous strain within the sample. Only at steady state does a stable asymmetrical texture also reflect the vorticity of the whole sample. (2) The transition from a symmetrical cross-girdle to an oblique point maxima pattern is strain-dependent. Considered together, these two points suggest that texture patterns can only be used to infer the degree of strain coaxiality on a larger scale if independent criteria are available to indicate that the microstructurc has attained steady state. Steady state is difficult to define because not all microstructural elements become strain-invariant simultaneously and on the same scale. Our experiments show that a strongly domainal, high temperature microfabric is not at steady state. However, a certain degree of microstructural heterogeneity is always present on the grain scale, even at steady state. In the absence of reliable microstructural criteria for steady state, we suggest that an angle of approximately $7^{\circ}$ or less between the main schistosity $\left(S_{\mathrm{a}}\right.$ microshears) and the SZB indicates that sufficiently high shear strains have accrued for a steadystate microfabric to have formed in high-temperature mylonite. This angle corresponds to $\gamma=8$, the minimum shear strain necessary to attain microstructural and textural steady-state in our experiments. (3) The finite strain at steady state is highly heterogeneous on several scales of observation. Shear zones rotate and their shear sense can change during deformation within the host shear zone. The local sense of shear does not necessarily reflect the large-scale kinematics, even in bulk plane strain, simple shear. Therefore, care should be taken always to consider the bulk shear strain and the pattern of shearing within the entire large-scale shear zone. Straindependent changes in shear sense are conceivable on all geological scales, including that of tectonic plate margins! (4) Finally, steady state is characterized by an assemblage of mechanisms whose relative activity does not vary with strain. However, the temperature and strain rate sensitivities of this mechanism assemblage are still unknown. Work is in progress to clarify how variations in the ambient conditions of shearing affect the microfabric.

Acknowledgements-We wish to thank P. Bons and C. ten Brink for their generous help in introducing us to the preparation and handling of analogue materials. P. Bons, M. Jessell and R. Panozzo were most obliging in providing us with copies of the computer programs MARKER ANALYSIS, SURFOR and PAROR. Special thanks also go to P. Bons, J. Ree, J. Tullis and J. Urai for informal reviews of this article, as well as to Ch. Pauli, S. M. Schmid, G. Schreurs, H. Stünitz and R. Zurbriggen for stimulating discussions. W. D. Means kindly provided us with reprints as well as helpful tips and written encouragement at several crucial points in our experimental program. Finally, the paper benefited from the detailed reviews and comments of the Journal's two referees, R. Law and M. Jessell. The financial support of the Schweizerische Nationalfonds in the form of Profil-2 Grant No. 2130598.91 and Project No. 21-33814.92 is gratefully acknowledged.

so 18:5-k

\section{REFERENCES}

Bons, P. D. 1993. Experimental deformation of polyphase rock analogues. Geol. Ultrajectina 110.

Bons, P., Jessell, M. \& Passchier, C. W. 1993. The analysis of progressive deformation in rock analogues. J. Struct. Geol. 15, 403412.

Bouchez, J. L. \& Duval, P. 1982. The fabric of polycrystalline ice deformed in simple shear: Experiments in torsion, natural deformation and geometrical interpretation. Text. \& Microstruct. 5, 171190.

Carreras, J., Estrada, A. \& White, S. 1977. The effect of folding on the $c$-axis fabrics of a quartz mylonite. Tectonophysics 39, 3-24.

Carreras, J. \& Garcia Celma, A. 1982. Quartz $c$-axis fabric variation at the margins of a shear zone developed in schists from Cap de Creus. Acta Geol. Hispàn. T17, 137-149.

Cobbold, P. R. \& Gapais, D. 1986. Slip-system domains. I. planestrain kinematics of arrays of coherent bands with twinned fibre orientations. Tectonophysics 131, 113-132.

Drury, M. R. \& Humphreys, F. J. 1986. The development of microstructure in $\mathrm{Al}-5 \% \mathrm{Mg}$ during high temperature deformation. Acta. metall. 34, 2259-2271.

Drury, M. R. \& Humphreys, F. J. 1988. Microstructural shear criteria associated with grain-boundary sliding during ductile deformation. J. Struct. Geol. 10, 83-89.

Drury, M. R. \& Urai, J. L. 1990. Deformation-related recrystallization processes. Tectonophysics 172, 235-253.

Etchecopar, A. 1977. A plane kinematic model of progressive deformation in a polycrystalline aggregate. Tectonophysics 39, 121-139.

Etchecopar, A. \& Vasseur, G. 1987. A 3-D kinematic model of fabric development in polycrystalline aggregates: comparison with experimental and natural examples. J. Struct. Geol. 9, 705-717.

Fueten, F., Robin, P. F. \& Stephens, R. 1991. A model for the development of a domainal quartz $c$-axis fabric in a coarse grained gneiss. J. Struct. Geol. 13, 1111-1124.

Garcia Celma, A. 1982. Domainal and fabric heterogeneities in Cap de Creus quartz mylonites. J. Struct. Geol. 4, 443-455.

Gleason, G. C., Tullis, J. \& Heidelbach, F. 1993. The role of dynamic recrystallization in the development of lattice preferred orientations in cxperimentally deformed quartz aggregates. J. Struct. Geol. 15, $1145-1168$.

Hirth, G. \& Tullis, J. 1992. Dislocation creep regimes in quartz aggregates. J. Struct. Geol. 14, 145-189.

Hudleston, P. J, 1978. Progressive deformation and development of fabric across zones of shear in glacial ice. In: Energetics of Geologi. cal Processes (edited by Saxena, S. \& Bhattacharji, S.). Springer, Berlin, 121-150.

Jessell, M. W. 1986. Grain boundary migration and fabric development in experimentally deformed octachloropropane. J. Struct. Geol. 8, 527-542.

Jessell, M. W. 1988. Simulation of fabric development in recrystallizing aggregates-I. Description of the model. J. Struct. Geol. 10, 771-778.

Jessell, M. W. \& Lister, G. S. 1990. A simulation of the temperature dependence of quartz fabrics. In: Deformation Mechanisms, Rheology and Tectonics (edited by Knipe, R. J. \& Rutter, E. H.). Spec. Publs geol. Soc. Lond. 54, 353-362.

Knipe, R. J. 1989. Deformation mechanisms-recognition from natural tectonites. J. Struct. Geol. 11, 127-146.

Knipe, R. J. \& Law, R. D. 1987. The influence of crystallographic orientation and grain boundary migration on microstructural and textural evolution in an S-C mylonite. Tectonophysics 135, 155-169.

Kruhl, J. H. \& Voll, G. 1976. Fabrics and metamorphism from the Monte Rosa Root Zone into the Ivrea Zone near Finero, Southern margin of the Alps. Schweiz. miner. petrogr. Mitt. 56, 627-633.

Law, R. D. 1990 . Crystallographic fabrics: a selective review of their application to research in structural geology. In: Deformation Mech anisms, Rheology and Tectonics (cditcd by Knipe, R. J. \& Rutter, E. H.). Spec. Publs geol. Soc. Lond. 54, 335-352.

Lister, G. S. 1982. A vorticity equation for lattice reorientation during plastic deformation. Tectonophysics 82, 351-366.

Lister, G. S. \& Dornsiepen, U. F. 1982. Fabric transition in the Saxony granulite terrain. J. Struct. Geol. 4, 81-92.

Lister, G. S. \& Hobbs, B. E. 1980. The simulation of fabric development during plastic deformation and its application to quartzite: the influence of deformation history. J. Struct. Geol. 2, 355-370.

Lister, G. S., Paterson, M. S \& Hobbs, B. E. 1978. The simulation of fabric development during plastic deformation and its application to quartzite: the model. Tectonophysics 45, 107-158. 
Lister, G. S. \& Snoke, A. W. 1984. S-C mylonites. J. Struct. Geol. 6, $617-638$.

Lister, G. S. \& Williams, P. F. 1983. The partitioning of deformation in flowing rock masses. Tectonophysics 92, 1-33.

Lloyd, G. E., Law, R. D., Mainprice, D. \& Wheeler, J. 1992. Microstructural and crystal fabric evolution during shear zone formation. J. Struct. Geol. 14, 1079-1100.

Means, W. D. 1980. High temperature simple-shearing fabrics: a new experimental approach. J. Struct. Geol. 2, 197-202.

Means, W. D. 1981. The concept of steady-state foliation. Tectonophysics 78, 179-199.

Means, W. D. 1989a. Stretching faults. Geology 17, 893-896.

Means, W. D. 1989 b. Synkinematic microscopy of transparent polycrystals. J. Struct. Geol. 11, 163-174.

Means, W. D. \& Dong, H. G. 1982. Some unexpected effects of recrystallization on the microstructures of materials deformed at high temperature. Mitt. Geol. Inst. ETH 239, 205-207.

Panozzo, R. 1983. Two-dimensional analysis of shape-fabric using projections of digitized lines in a plane. Tectonophysics 95, 279-294.

Panozzo, R. 1984. Two-dimensional strain from the orientation of lines in a plane. J. Struct. Geol. 6, 215221.

Panozzo, R. \& Pauli, CH. 1993. Integrated spatial and orientation analysis of quartz c-axes by computer-aided microscopy. J. Struct. Geol. 15, 369-383.

Platt, J. P. 1984. Secondary cleavages in ductile shear zones. J. Struct. Geol. 6, 439-442.

Poirier, J. P. \& Guillope, M. 1979. Deformation induced recrystallization of minerals. Bull. Mineral. 102, 67-74.

Ramsauer, H. 1941. Achsenverteilungsanalysen an Quarztektoniten. Unpublished Ph.D. thesis, University of Innsbruck, Austria.

Rasband, W. 1992. Image 1.28. Public Domain Software. National Institute of Health, Research Services Branch NIMH, Bethesda, Maryland.

Ree, J. H. 1990. High temperature deformation of octachloropropane: dynamic grain growth and lattice reorientation. In: Defor mation Mechanisms, Rheology and Tectonic (edited by Knipe, R. J. \& Rutter, E. H.). Spec. Publs geol. Soc. Lond. 54, 363-368.

Ree, J. H. 1991. An experimental steady-state foliation. J. Struct. Geol. 13, 1001-1011.

Ree, J. H. 1994. Grain boundary sliding and development of grain boundary openings in experimentally deformed octachloropropane. J. Struct. Geol. 16, 403-418.

Sander, B. 1950. Einführung in die Gefügekunde der geologischen Körper, zweiter Teil: Die Korngefüge. Springer, Berlin, 409.
Schmid, S. M. 1994. Textures of geological materials: computer model predictions versus empirical interpretations based on rock deformation experiments and field studies. In: Textures of Geological Materials (edited by Bunge, H. J., Siegesmund, S., Skrotzi, W. \& Weber, K.). DGM Informationsgesellschaft, 279-301.

Schmid, S. M. \& Casey, M. 1986. Complete fabric analysis of some commonly obscrved quartz c-axis patterns. In: Material and Rock Deformation: Laboratory Studies-The Patterson Volume (edited by Hobbs, B. E. \& Heard, H. C.). Am. Geophys. Un. Geophys. Monogr. 36, 161-199.

Schmid, S. M. \& Handy, M. R. 1991. Towards a genetic classification of fault rocks: geological usage and tectonophysical implications. In: Controversies in Modern Geology (edited by Müller, D. W., McKenzie, J. A. \& Weissert, H.). Academic Press, New York, 95110.

Schmid, S. M., Zingg, A. \& Handy, M. R. 1987. The kinematics of movements along the Insubric Line and the emplacement of the Ivrea Zone. Tectonophysics 135, 47-66.

Simpson, C. \& Schmid, S. M. 1983. An evaluation of criteria to deduce the sense of movement in sheared rocks. Bull. geol. Soc. Am. 94, 1281-1288.

Tullis, J., Christie, J. M. \& Griggs, D. T. 1973. Microstructures and preferred orientations of experimentally deformed quartzites. Bull. geol. Soc. Am. 84, 297-314.

Tullis, J. \& Tullis, A. 1986. Experimental rock deforming techniques. In: Mineral and Rock Deformation: Laboratory Studies-The Paterson Volume (edited by Hobbs, B. E. \& Heard, H. C.). Am. Geophys. Un. Geophys. Monogr. 36, 297-324.

Urai, J. L. \& Humphreys, F. J. 1980. In-situ studies of the deformation and dynamic recrystallization of rhombohedral camphor. J. Mater. Sci. 15, 1231-1240.

Urai, I. I.., Means, W. D. \& Lister, G. S. 1986. Dynamic recrystallization of minerals. In: Mineral and Rock Deformation: Laboratory Studies-The Paterson Volume (edited by Hobbs, B. E. \& Heard, H. C.). Am. Geophys. Un. Geophys. Monogr. 36, 161-199.

Vernon, R. H. 1976. Metamorphic processes, Reactions and Microstructure Development. George Allen \& Unwin, London.

Wenk, H.-R., Canova, G., Molinari, A. \& Kocks, U. F. 1989. Viscoplastic modelling of texture development in quartzite. $J$. geophys. Res. 94, 17,895-17,906.

Wilson, C. J. L. \& Russell-Head, D. S. 1982. Steady state preferred orientation of ice deformed in plane strain at $-1^{\circ} \mathrm{C}$. J. Glaciol. 2, 145-160. 